\title{
Frontostriatal Circuit Dynamics Correlate with Cocaine Cue-Evoked Behavioral Arousal during Early Abstinence ${ }^{1,2,3}$
}

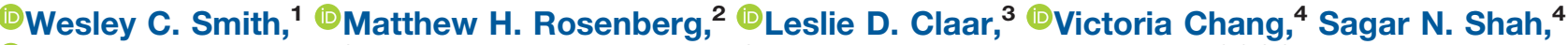 \\ (1)Wendy M. Walwyn, ${ }^{5,6,7}$ Christopher J. Evans, ${ }^{5,6,7}$ and Sotiris C. Masmanidis ${ }^{1,2,3,6,8}$
}

\section{DOI:http://dx.doi.org/10.1523/ENEURO.0105-16.2016}

\begin{abstract}
${ }^{1}$ Interdepartmental PhD Program in Neuroscience, University of California, Los Angeles, Los Angeles, California 90095, 2Department of Neurobiology, University of California, Los Angeles, Los Angeles, California 90095, ${ }^{3}$ Department of Bioengineering, University of California, Los Angeles, Los Angeles, California 90095, ${ }^{4}$ Undergraduate Interdepartmental Program for Neuroscience, University of California, Los Angeles, Los Angeles, California 90095, ${ }^{5}$ Department of Psychiatry and Biobehavioral Sciences, University of California, Los Angeles, Los Angeles, California 90095, ${ }^{6}$ Brain Research Institute, University of California, Los Angeles, Los Angeles, California 90095, ${ }^{7}$ Hatos Center for Neuropharmacology, Semel Institute for Neuroscience and Human Behavior, University of California, Los Angeles, Los Angeles, California 90095, and ${ }^{8}$ California Nanosystems Institute, University of California, Los Angeles, Los
\end{abstract} Angeles, California 90095

\section{Visual Overview}

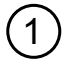

Simultaneous prefrontal / ventral striatal recordings and pupillometry in head-fixed, cocaine-conditioned mice after one day of abstinence.

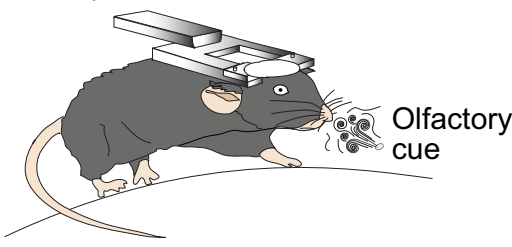

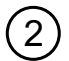

Cocaine-associated olfactory cues selectively increase pupil dilation.

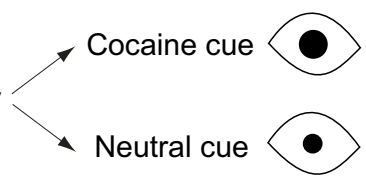

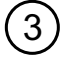

Cocaine cue-evoked pupil dilation correlates with frontostriatal activity.

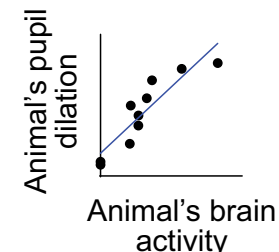

It is thought that frontostriatal circuits play an important role in mediating conditioned behavioral responses to environmental stimuli that were previously encountered during drug administration. However, the neural correlates of conditioned responses to

drug-associated cues are not well understood at the level of large populations of simultaneously recorded neurons, or at the level of local field potential (LFP) synchrony in the frontostriatal network. Here we introduce a behavioral assay of conditioned arousal to cocaine cues involving pupillometry in awake head-restrained mice. After just $24 \mathrm{~h}$ of drug abstinence, brief exposures to olfactory stimuli previously paired with cocaine injections led to a transient dilation of the pupil, which was greater than the dilation effect to neutral cues. In contrast, there was no cue-selective change in locomotion, as measured by the rotation of a circular treadmill. The behavioral assay

\section{Significance Statement}

Frontostriatal circuits are implicated in drug craving and relapse, which can be triggered during abstinence by drug-associated cues. This study used large-scale neural recordings with silicon microprobe technology to simultaneously examine prefrontal and striatal activity in cocaine-conditioned mice. We found relationships among the level of cocaine cue-evoked neural inhibition, frontostriatal network synchrony, and conditioned arousal measured via pupillometry. This work shows that pupil dilation is a highly sensitive measure of arousal to cocaine cues. Furthermore, the results demonstrate the effectiveness of using large-scale recordings spanning multiple brain areas to examine the neural correlates of interindividual variability among drug-experienced animals. 
was combined with simultaneous recordings from dozens of electrophysiologically identified units in the medial prefrontal cortex (mPFC) and ventral striatum (VS). We found significant relationships between cocaine cueevoked pupil dilation and the proportion of inhibited principal cells in the mPFC and VS. Additionally, LFP coherence analysis revealed a significant correlation between pupillary response and synchrony in the $25-45 \mathrm{~Hz}$ frequency band. Together, these results show that pupil dilation is sensitive to drug-associated cues during acute stages of abstinence, and that individual animal differences in this behavioral arousal response can be explained by two complementary measures of frontostriatal network activity.

Key words: cocaine; conditioned arousal; large-scale recordings; prefrontal cortex; pupillometry; striatum

\section{Introduction}

Environmental stimuli formerly associated with drugs can have a powerful influence on behavior, presenting a long-term risk of relapse after the cessation of drug use (Robinson and Berridge, 1993; O'Brien et al., 1998). This is thought to occur because of functional changes in a variety of brain circuits mediating reward learning, motivation, arousal, and inhibitory behavioral control, which persist in drug abstinence (Everitt and Robbins, 2005; Britt et al., 2012; Muñoz-Cuevas et al., 2013; Lüthi and Lüscher, 2014; MacAskill et al., 2014; Pascoli et al., 2014). The medial prefrontal cortex (mPFC) and ventral striatum (VS) are two interconnected areas, which are believed to play a critical role in these processes (Jentsch and Taylor, 1999; Kalivas et al., 2005; Day and Carelli, 2007; Goldstein and Volkow, 2011). Neuroimaging studies in addicted human subjects have revealed that prefrontal and striatal regions are modulated by cocaine-associated cues (Maas et al., 1998; Childress et al., 1999; Wexler et al., 2001), and that some of these activation patterns correlate with self-reported drug craving (Bonson et al., 2002). Neuroimaging has also revealed alterations in frontostriatal network connectivity following drug use (Wilcox et al., 2011; Hu et al., 2015). However, because of the limited spatiotemporal resolution of neuroimaging techniques, little is known about the neurophysiological correlates of cocaine cue-evoked frontostriatal interactions. At the level of single-neuron measurements, units in the $\mathrm{mPFC}$ and VS are known to encode drug-associated cues (Carelli et al., 1993; Chang et al., 2000; Ghitza et al., 2003; Rebec and Sun, 2005; West et al., 2014). However, while individual animal differences in behavioral responses to

Received May 3, 2016; accepted June 5, 2016; First published June 16, 2016. ${ }^{1}$ The authors declare no competing financial interests.

${ }^{2}$ Author contributions: W.C.S., W.M.W., C.J.E., and S.C.M. designed research; W.C.S., M.H.R., L.D.C., V.C., and S.N.S. performed research; W.C.S. and S.C.M. analyzed data; W.C.S. and S.C.M. wrote the paper.

${ }^{3}$ W.C.S. was supported by National Institutes of Health (NIH) Predoctoral Training Grant on Drugs of Abuse T32-DA-024635. W.M.W. and C.J.E. were supported by NIH Grant DA-05010 and by the Shirley and Stefan Hatos Foundation. S.C.M. received support from the Alfred P. Sloan Foundation, a McKnight Technical Innovations in Neuroscience Award, National Science Foundation Chemical, Bioengineering, Environmental, and Transport Systems (CBET) Grant 1263785, and NIH Grant R01-DA-034178.

Correspondence should be addressed to Sotiris C. Masmanidis, University of California, Los Angeles, Los Angeles, CA 90095. E-mail: smasmanidis@ucla.edu.

DOI:http://dx.doi.org/10.1523/ENEURO.0105-16.2016

Copyright (C) 2016 Smith et al.

This is an open-access article distributed under the terms of the Creative Commons Attribution 4.0 International, which permits unrestricted use, distribution and reproduction in any medium provided that the original work is properly attributed. drugs and their associated stimuli can be significant (Groman et al., 2012; Chen et al., 2013; Muñoz-Cuevas et al., 2013; Robinson et al., 2014; Storey et al., 2016), the neural correlates of this interindividual variability are not well understood. Large-scale recordings have the potential to identify novel relationships between neural activity in prefrontal and striatal circuits and drug cue-evoked behavior, but until now, such measurements have not been widely used together with animal models of addiction.

In addition to eliciting voluntary behavioral responses or subjectively measured craving, drug-associated cues are known to influence autonomic responses, indicating a heightened state of arousal in the form of heart rate and skin conductance changes (Ehrman et al., 1992) and pupil dilation (Rosse et al., 1995). Since the dynamics of prefrontal and other cortical circuits are related to pupil diameter (Aston-Jones and Cohen, 2005; Reimer et al., 2014; McGinley et al., 2015; Vinck et al., 2015; Joshi et al., 2016), which in turn reflects arousal (Hess and Polt, 1960; Bradley et al., 2008), we hypothesized that, during abstinence, drug-associated stimuli cause pupil dilation, that the degree of this effect varies among animals, and that this variability correlates with the dynamics of frontostriatal circuits.

To address this hypothesis, here we simultaneously performed large-scale in vivo neural recordings in the mPFC and VS together with a novel assay of conditioned arousal to cocaine-associated cues in mice in the early stage (first $24 \mathrm{~h}$ ) of abstinence, which relies on pupil dilation measurements. We found that cocaine-paired olfactory cues induced a stronger pupillary response than saline-paired cues, and that this autonomic response was more selective for cocaine cues than the cue-evoked locomotion response. Large-scale recordings were performed with a customized 512 electrode silicon microprobe (Shobe et al., 2015), providing simultaneous measurements from dozens of electrophysiologically identified neurons in the MPFC and VS, as well as local field potential (LFP) oscillations. We assessed spontaneous and cue-evoked electrophysiological firing properties, and related the level of activation and inhibition to simultaneously measured changes in pupil diameter. We found that the proportion of prefrontal pyramidal cells and striatal projection neurons that were inhibited by cocaineassociated cues was correlated with the degree of pupil dilation. Moreover, we found that $25-45 \mathrm{~Hz}$ frontostriatal LFP coherence was correlated with the pupillary response. Together, these results suggest that suppression of frontostriatal activity, and elevated interregional syn- 
chrony, have a related role in triggering arousal to cocaine cues. These measurements provide new insights into the dynamics of frontostriatal circuits when drug-free animals are exposed to stimuli that were previously encountered during drug administration.

\section{Materials and Methods}

\section{Animals and surgical procedures}

All procedures were approved by the University of California, Los Angeles, Animal Care Committee. We used singly housed male C57BL/6J mice (12-16 weeks old; The Jackson Laboratory), with 10 mice receiving alternating cocaine and saline injections (referred to as the drug group) and 7 mice receiving only saline (referred to as the control group). Animals underwent an initial surgery under isoflurane anesthesia in a stereotactic apparatus to implant stainless steel head restraint bars bilaterally into their skulls using dental cement (Shobe et al., 2015). Animals were anesthetized with isoflurane for a second surgery on the evening prior to the day of the recording session to make a craniotomy over the anterior striatum and MPFC in the right hemisphere. The dura mater was opened to facilitate the insertion of microprobes during the recording session. An additional craniotomy was made over the posterior cerebellum for placement of a silver/silver chloride electrical reference wire. The craniotomies were covered with silicone elastomer sealant (Kwik-Cast, WPI) to seal the exposed skull.

\section{Cocaine conditioning}

One week after the first surgery, animals began habituation to head restraint and the behavioral conditioning/ testing room for $4 \mathrm{~d}$, with one 30 min session per day. Animals were mounted with the head bar bracket on top of a $200-\mathrm{mm}$-diameter treadmill ball that was free to rotate forward and backward. No other stimuli were presented during habituation, except for low background lighting in the enclosed room provided by four 200 lumen LED lamps directed away from the eyes of the mice and toward the walls of the room. The lamps were necessary to prevent a saturation effect in the pupil dilation, which would occur in the absence of any light. After habituation, fully awake head-restrained animals were conditioned over $10 \mathrm{~d}$ to injections of cocaine or saline, paired with a previously unfamiliar olfactory cue. Each daily conditioning session for the drug group was devoted to either cocaine or saline, but never both on the same day. The drug group received alternating cocaine $(15 \mathrm{mg} / \mathrm{kg}, 100$ $\mu$ l, s.c.) or saline (100 $\mu$ l, s.c.) infusions administered over a $1 \mathrm{~min}$ period. The infusions were given by means of a syringe pump connected to a 27.5 gauge syringe needle inserted subcutaneously. We removed the needle after each session. To ensure consistency across training and behavioral testing (see next section), we also inserted the needle during the testing session, but it was disconnected from any fluid delivery system. Conditioning started with saline on day 1 and ended with cocaine on day 10. All cocaine or saline administration sessions were paired with a single continuous presentation of odorized air, starting 5 min preinjection and ending 25 min postinjection, when the animal was removed from the conditioning room and returned to its home cage in a vivarium housing facility. Olfactory cues were introduced via an olfactometer by bubbling air $(0.15 \mathrm{~L} / \mathrm{min})$ through aromatic liquids (citral or isoamyl acetate) diluted $1: 10$ in mineral oil (SigmaAldrich), and mixing this product with a $1.5 \mathrm{~L} / \mathrm{min}$ stream of air. This mixture flowed through a tube passing $15 \mathrm{~mm}$ away from, and perpendicularly to the animal's nose, with a $5 \mathrm{~mm}$ opening in the tube aimed at the nose. Half of the drug group animals were counterbalanced and received the opposite drug-odor pairing. The saline group received saline injections during all $10 \mathrm{~d}$ of conditioning, paired with alternating citral and isoamyl acetate cues. During each conditioning session, we monitored behavior in the form of treadmill rotation velocity and pupil dilation. Pupillometry video was captured under infrared illumination with the camera (model acA640, Basler) focused on the right eye of the animal.

\section{Behavioral testing}

The craniotomy surgery was performed $7-8 \mathrm{~h}$ after the final conditioning session. Behavioral testing and electrophysiological recordings were performed simultaneously in drug-free conditions, in animals abstinent from their last injection of cocaine (drug group) or saline (control group) for $24 \pm 3 \mathrm{~h}$. We provided animals a $15 \mathrm{~min}$ resting period without any cues, which was used to capture spontaneous activity. Subsequently, we randomly presented the previously paired odors ( $15 \mathrm{~s}$ in length, 30 trials per odor type, with a randomized mean intertrial interval of $20 \pm 5$ s) while monitoring treadmill locomotion and pupil dilation to assess behavioral responses.

\section{Electrophysiological recordings}

A silicon microprobe (Shobe et al., 2015) was assembled targeting the medial prefrontal cortex and ventral striatum (256 electrodes per area, total of 512 electrodes). Each area was targeted with four silicon prongs spaced $0.2 \mathrm{~mm}$ apart, each containing 64 electrodes that were arranged in a hexagonal array pattern spanning $1.05 \mathrm{~mm}$ along the dorsal-ventral axis. Electrodes had an area of $100 \mu \mathrm{m}^{2}$ and were gold plated (noncyanide gold solution, Sifco) to an impedance of 0.1-0.5 M $\Omega$. In the mPFC, the relatively long span of the electrode array allowed us to simultaneously record from the prelimbic and infralimbic subregions. In the VS, the primary target was the nucleus accumbens core, but, due to the length of the electrode array, we also recorded from the region above the accumbens core (medial striatum). One to two hours prior to recording, the silicon microprobes were coated with a drop of fluorescent dye (DiD, Invitrogen) to assist with histological confirmation of their position. Animals were then mounted on the head restraint system. An electrical reference wire was placed on the cerebellar surface, covered in ACSF-saturated water-absorbing foam (Gelfoam), to improve electrical contact, and sealed with silicone elastomer (Kwik-Cast, WPI). The silicon microprobes were slowly inserted to stereotactically defined coordinates with a motorized micromanipulator (MP-285, Sutter Instruments). The tip position of the most medial shaft in the $\mathrm{mPFC}$ was targeted to $1.90 \mathrm{~mm}$ anterior, $0.07 \mathrm{~mm}$ lateral, 
Table 1: Number of cortical pyramidal units per animal in the drug-treated group

\begin{tabular}{|c|c|c|c|c|c|}
\hline Mouse ID & $\begin{array}{l}\text { Total Pyramidal } \\
\text { cells }\end{array}$ & $\begin{array}{l}\text { Pyramidal cells excited } \\
\text { by cocaine cues }\end{array}$ & $\begin{array}{l}\text { Pyramidal cells inhibited } \\
\text { by cocaine cues }\end{array}$ & $\begin{array}{l}\text { Pyramidal cells excited } \\
\text { by saline cues }\end{array}$ & $\begin{array}{l}\text { Pyramidal cells inhibited } \\
\text { by saline cues }\end{array}$ \\
\hline 1 & 84 & 18 & 26 & 11 & 23 \\
\hline 2 & 141 & 13 & 21 & 14 & 28 \\
\hline 3 & 87 & 17 & 15 & 16 & 10 \\
\hline 4 & 57 & 3 & 6 & 14 & 24 \\
\hline 5 & 58 & 16 & 7 & 5 & 5 \\
\hline 6 & 95 & 22 & 15 & 8 & 5 \\
\hline 7 & 31 & 6 & 10 & 1 & 6 \\
\hline 8 & 67 & 10 & 6 & 11 & 10 \\
\hline 9 & 27 & 4 & 1 & 0 & 2 \\
\hline 10 & 39 & 8 & 5 & 12 & 0 \\
\hline
\end{tabular}

and $3.40 \mathrm{~mm}$ ventral relative to bregma in the right hemisphere. The tip of the most medial shaft in the VS was placed in the same hemisphere at $1.0 \mathrm{~mm}$ anterior, 0.77 $\mathrm{mm}$ lateral, and $4.70 \mathrm{~mm}$ ventral relative to bregma. The insertion was monitored with a surgical microscope. After reaching the target depth, a drop of mineral oil was placed on the exposed cortical surface, and a 45 min settling period elapsed before beginning the electrophysiological data acquisition and behavioral testing (see the previous section). We monitored electrophysiological data at a sampling rate of $25 \mathrm{kHz} /$ electrode, together with treadmill ball rotation and olfactory cue delivery time at a sampling rate of $10 \mathrm{kHz}$. Pupillometry video was synchronously captured at 25 frames/s. Following each recording, the microprobe was cleaned in trypsin solution (Invitrogen), rinsed with deionized water and ethanol, and reused throughout these experiments.

\section{Histology}

Coronal brain sections were sliced at $100 \mu \mathrm{m}$ on a vibratome, and individual sections were placed in order onto a 24 well plate containing ice-cold PBS solution. We then performed immunohistochemistry using standard procedures on the mPFC and striatal sections to determine the placement of the silicon prongs in each region. Sections were stained for neuronal nuclei with chicken- $\alpha$ NeuN primary antibodies (D3S3I, Cell Signaling Technology) and fluorescent $\alpha$-chicken secondary antibodies (Alexa Fluor 488, Jackson ImmunoResearch). DiD, which diffusively labeled tissue near the probe insertion sites, was used to estimate the final probe position.

\section{Unit classification}

Spike sorting was performed using a semi-automated spike waveform template-matching algorithm (Shobe et al., 2015). Each unit was assigned an estimated 3D coordinate as well as a histologically determined brain region. The estimated position coincided with the recording site exhibiting the highest spike amplitude for that unit. Finally, units were classified as principal neurons or interneurons in their respective brain regions. Striatal units with a minimum baseline rate of $0.02 \mathrm{~Hz}$ were classified as putative medium spiny projection neurons (MSNs), fastspiking interneurons (FSIs), or tonically active neurons (TANs), based on spike waveform peak-to-trough width and the coefficient of variation of the baseline firing rate
(Barthó et al., 2004; Bakhurin et al., 2016). FSls were characterized by a narrow spike waveform (maximum width, $0.475 \mathrm{~ms}$ ). MSNs and TANs both have wider waveforms (minimum width, $0.55 \mathrm{~ms}$; maximum width, 1.25 $\mathrm{ms})$. TANs were separated from MSNs by the regularity of their baseline firing (maximum coefficient of variation, 1.5). Units in the mPFC were classified as putative FSIs or pyramidal neurons using the same spike width separation criterion as described above (Tseng et al., 2006).

\section{Behavioral data analysis}

Pupil diameter data were extracted from video frames with the MATLAB image analysis toolbox and custom scripts. To quantify behavioral responses during cocaine or saline conditioning, we calculated the mean postinjection treadmill rotation velocity and pupil diameter per animal. To quantify the cue-evoked behavioral responses during abstinence, for each animal we calculated the change in speed and pupil diameter during the $15 \mathrm{~s}$ cue presentation time relative to a $1 \mathrm{~s}$ baseline period prior to cue onset. Unless otherwise noted, responses were averaged across all 30 cocaine or saline-paired trials.

\section{Electrophysiological data analysis}

The single-unit firing rate was calculated in time steps of $50 \mathrm{~ms}$ and smoothed by convolving with a Gaussian kernel (SD = $250 \mathrm{~ms}$ ). Spontaneous firing activity was obtained by averaging the rate from the first 15 min of the recording, when animals received no olfactory cues and did not move on the treadmill. Cue-evoked activity was obtained by averaging across all cocaine- or saline-paired trials. To determine whether units were excited or inhibited by cues, we performed a permutation test to identify time bins whose firing rate was significantly different from a $1 \mathrm{~s}$ baseline period preceding the cue onset (criterion for significance, $p<0.01$ ). If two or more consecutive time bins during the cue presentation period ( $t=0-15 \mathrm{~s}$ from cue onset) were significantly greater (less) than the baseline, the unit was classified as excited (inhibited). Tables 1 and 2 list the number of total, excited, and inhibited pyramidal cells and MSNs per animal in the drug-treated group ( $n=10$ mice). Partitioning of units into different subregions was done using an objective criterion: all units recorded from the top half of the electrode array were assigned to one partition, and the remaining units were assigned to the other partition. We confirmed histologi- 
Table 2: Number of striatal MSN units per animal in the drug-treated group

\begin{tabular}{|c|c|c|c|c|c|}
\hline Mouse ID & Total MSNs & $\begin{array}{l}\text { MSNs excited } \\
\text { by cocaine cues }\end{array}$ & $\begin{array}{l}\text { MSNs inhibited } \\
\text { by cocaine cues }\end{array}$ & $\begin{array}{l}\text { MSNs excited } \\
\text { by saline cues }\end{array}$ & $\begin{array}{l}\text { MSNs inhibited } \\
\text { by saline cues }\end{array}$ \\
\hline 1 & 95 & 11 & 27 & 8 & 29 \\
\hline 2 & 63 & 3 & 12 & 4 & 21 \\
\hline 3 & 87 & 8 & 15 & 3 & 17 \\
\hline 4 & 60 & 5 & 8 & 8 & 11 \\
\hline 5 & 65 & 9 & 9 & 5 & 9 \\
\hline 6 & 100 & 11 & 22 & 6 & 4 \\
\hline 7 & 21 & 5 & 6 & 3 & 0 \\
\hline 8 & 81 & 3 & 17 & 5 & 16 \\
\hline 9 & 57 & 6 & 3 & 2 & 6 \\
\hline 10 & 81 & 7 & 14 & 10 & 9 \\
\hline
\end{tabular}

cally that the top and bottom partitions in the mPFC corresponded approximately to the prelimbic and infralimbic cortices, respectively. In the VS, the top and bottom partitions corresponded approximately to the medial striatum and nucleus accumbens core, respectively. Local field potential signals were downsampled off-line to 1 $\mathrm{kHz}$. To quantify the cue-evoked change in LFP coherence, for each animal we calculated the change in 25-45 $\mathrm{Hz}$ coherence during the $15 \mathrm{~s}$ cue presentation time relative to a $1 \mathrm{~s}$ baseline period prior to cue onset. Coherence changes were averaged across all cocaine- or saline-paired trials.

\section{Statistics}

Table 3 contains a list of the statistical tests performed and their results. Permutation tests to determine significant cue-evoked excitation or inhibition of neural activity were performed with custom Matlab scripts (Shobe et al., 2015). All other statistical analysis was performed with standard Matlab functions or GraphPad Prism software. ANOVA was followed by Sidak's correction for multiple comparisons. Analysis of neural activity in different electrode partitions was followed by Bonferroni's correction for two comparisons, corresponding to the top and bottom partitions ( $\alpha$ was adjusted to 0.025). Correlations between pupillary response and neural activity or synchrony were reported with both Pearson's and Spearman's correlation coefficients ( $r$ and $r_{\mathrm{s}}$, respectively) to ensure consistency. In all cases, Pearson's and Spearman's correlations were in agreement with regard to the statistical significance of the result (both types of correlations are shown in Table 3).

\section{Results}

\section{Conditioned pupil dilation by cocaine-associated cues}

We developed a behavioral assay of arousal in response to cocaine-associated cues in fully awake, headrestrained mice (Fig. 1A). Before recording, mice in the drug group $(n=10)$ were conditioned over a $10 \mathrm{~d}$ period with alternating injections of cocaine and saline, which were paired with a specific olfactory cue (Fig. 1B). During this period, mice showed a psychomotor sensitization effect, as marked by increased rotational movement on the treadmill after doses of cocaine (Fig. 1C, left, $D$; two-way ANOVA: effect of treatment type: $F_{(1,18)}$
$=31.50, p<0.0001$; effect of treatment day: $F_{(4,72)}=$ 3.75, $p=0.008$; interaction effect: $F_{(4,72)}=2.64, p=$ $0.041)$. At the same time, mice showed increased pupil dilation in response to cocaine injections, which did not significantly change over the course of administration (Fig. 1C, right, E; two-way ANOVA: effect of treatment type: $F_{(1,18)}=17.66, p=0.0005$; effect of treatment day: $F_{(4,72)}=0.831, p=0.510$; interaction effect: $F_{(4,72)}$ $=0.65, p=0.627$ ).

After conditioning, animals were prepared for concomitant electrophysiological recording and behavioral testing. During behavioral testing, $24 \mathrm{~h}$ drug-abstinent animals were randomly exposed to olfactory cues previously associated with either cocaine or saline, but were not given any injections. While some animals moved in response to cues, we found no difference in cue-evoked treadmill rotation velocity between cocaine- and salinepaired odors (Fig. 1F; Wilcoxon matched pairs signedrank test, $p>0.99)$. In contrast, we found a significantly higher change in pupil diameter following the presentation of cocaine-paired cues (Fig. 1G; Wilcoxon matched pairs signed-rank test, $p=0.027)$. There was no correlation between cue-evoked changes in pupil dilation and locomotion in response to the cocaine-associated odor (Fig. $1 H, r=0.08, p=0.827$ ). Figure $1, l$ and $J$, shows the time dependence of average velocity and pupil diameter, respectively. Finally, we compared the mean pupillary response of the initial 15 trials and the final 15 trials, and found no consistent change in response to the drug cue (Fig. $1 K$; Wilcoxon matched pairs signed-rank test, $p=$ 0.695) or saline cue (Fig. 1L; Wilcoxon matched pairs signed-rank test, $p=0.922$ ), suggesting that elevated arousal in response to drug-associated cues is maintained throughout behavioral testing.

We confirmed our results by repeating conditioning and testing with a group of control animals $(n=7)$ that only received saline injections paired with the same two odors (Fig. 1B). Control animals showed no change in locomotion as a function of either odor type or day of treatment (Fig. 2A; two-way ANOVA, $p>0.05$ for all effects). Similarly, no changes were observed in pupil diameter during conditioning (Fig. $2 B$; two-way ANOVA, $p>0.05$ for all effects). On the test day, we found no statistical difference in either cue-evoked locomotion (Fig. 2C; Wilcoxon matched pairs signed-rank test, $p=0.297$ ) or pupil diameter (Fig. 2D; Wilcoxon matched pairs signed-rank test, $p$ 
Table 3: Statistical table

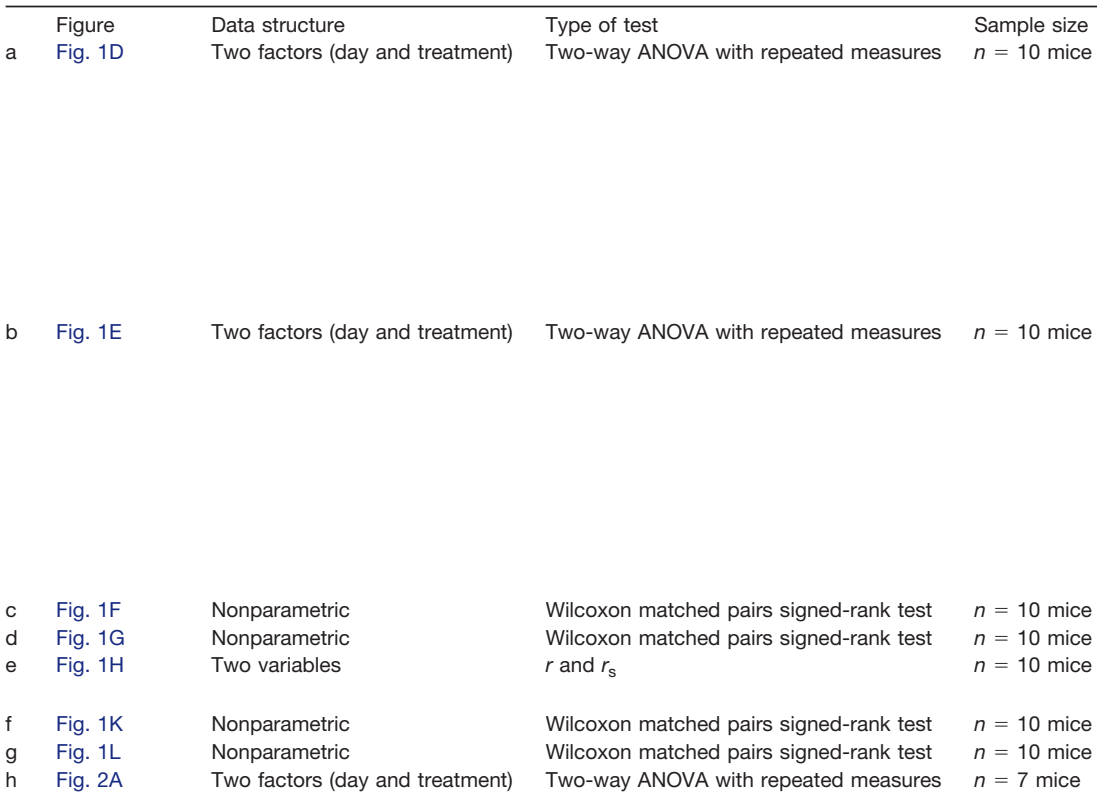

Wilcoxon matched pairs signed-rank test Wilcoxon matched pairs signed-rank test Mann-Whitney test

Mann-Whitney test

Mann-Whitney test

Mann-Whitney test

Mann-Whitney test

Mann-Whitney test

Mann-Whitney test

Mann-Whitney test

Kolmogorov-Smirnov test $n=7$ mice
$n=7$ mice
$n=7$ control group +10 drug group

$n=7$ control group +10 drug group

$n=7$ control group +10 drug group

$n=7$ control group +10 drug group

$n=7$ control group +10 drug group

$n=7$ control group +10 drug group

$n=7$ control group +10 drug group

$n=7$ control group +10 drug group

$n=26$ control +80 drug group FSIs $p$ Value

Day: $F_{(4,72)}=3.752, p=0.0079$ Treatment: $F_{(1,18)}=31.50, p<0.0001$ Interaction: $F_{(4,72)}=2.639, p=0.0407$ Sidak's multiple comparisons test: Saline vs drug, day 1: $p=0.2737$ Saline vs drug, day 2: $p=0.0630$ Saline vs drug, day 3: $p=0.0003$ Saline vs drug, day 4: $p<0.0001$ Saline vs drug, day 5: $p<0.0001$ Day: $F_{(4,72)}=0.8313, p=0.5096$ Treatment: $F_{(1,18)}=17.66, p=0.0005$ Interaction: $F_{(4,72)}=0.6524, p=0.6270$ Sidak's multiple comparisons test: Saline vs drug, day 1: $p=0.0148$ Saline vs drug, day 2: $p=0.0190$ Saline vs drug, day 3: $p=0.0004$ Saline vs drug, day $4: p=0.0013$ Saline vs drug, day $5: p=0.0034$ $p>0.9999$ $p=0.0273$

$r=0.080, p=0.827$

$r_{\mathrm{s}}=-0.103, p=0.785$

$p=0.6953$

$p=0.9219$

Day: $F_{(4,48)}=1.450, p=0.2320$

Treatment: $F_{(1,12)}=0.02449, p=0.8782$

Interaction: $F_{(4,48)}=0.4431, p=0.7768$

Sidak's multiple comparisons test:

Day 1: $p>0.9999$

Day 2: $p=0.9701$

Day 3: $p>0.9999$

Day 4: $p>0.9999$

Day $5: p=0.8377$

Day: $F_{(4,48)}=1.777, p=0.1489$

Treatment: $F_{(1,12)}=0.07157, p=0.7936$

Interaction: $F_{(4,48)}=0.2804, p=0.8893$

Sidak's multiple comparisons test:

Day 1: $p=0.9998$

Day 2: $p=0.9913$

Day 3: $p=0.9992$

Day 4: $p>0.9999$

Day 5: $p=0.9907$

$p=0.2969$

$p=0.3750$

$p=0.4028$

Bonferroni's correction: 2 comparisons, $\alpha=0.025$

$p=0.0328$

Bonferroni's correction: 2 comparisons, $\alpha=0.025$

$p=0.5942$

Bonferroni's correction: 2 comparisons, $\alpha=0.025$

Bonferroni's correction: 2 comparisons, $\alpha=0.025$

$p=0.9252$

Bonferroni's correction: 2 comparisons, $\alpha=0.025$

$p=0.4028$

Bonferroni's correction: 2 comparisons, $\alpha=0.025$

$p=0.3130$

Bonferroni's correction: 2 comparisons, $\alpha=0.025$

Bonferroni's correction: 2 comparisons, Bonferroni's

$p=0.7$

Bonferroni's correction: 2 comparisons, $\alpha=0.025$ 
Table 3: Continued

\begin{tabular}{|c|c|c|c|c|c|}
\hline & Figure & Data structure & Type of test & Sample size & $p$ Value \\
\hline u & Fig. 4G, right & Nonparametric & Kolmogorov-Smirnov test & $n=21$ control +60 drug group FSls & $\begin{array}{l}p=0.945 \\
\text { Bonferroni's correction: } 2 \text { comparisons, } \\
\alpha=0.025\end{array}$ \\
\hline v & Fig. $4 \mathrm{H}$, left & Nonparametric & Kolmogorov-Smirnov test & $n=102$ control +110 drug group FSIs & $\begin{array}{l}p=0.0584 \\
\text { Bonferroni's correction: } 2 \text { comparisons, } \\
\alpha=0.025\end{array}$ \\
\hline w & Fig. $4 \mathrm{H}$, right & Nonparametric & Kolmogorov-Smirnov test & $n=42$ control +97 drug group FSIs & $\begin{array}{l}p=0.349 \\
\text { Bonferroni's correction: } 2 \text { comparisons, } \\
\alpha=0.025\end{array}$ \\
\hline $\mathrm{x}$ & Fig. $5 \mathrm{E}$ & Nonparametric & Wilcoxon matched-pairs signed rank test & $n=10$ mice & $p=0.4316$ \\
\hline y & Fig. $5 \mathrm{~F}$ & Nonparametric & Wilcoxon matched-pairs signed rank test & $n=10$ mice & $p=0.6953$ \\
\hline$z$ & Fig. 5G & Nonparametric & Wilcoxon matched-pairs signed rank test & $n=10$ mice & $p=0.1602$ \\
\hline aa & Fig. $5 \mathrm{H}$ & Nonparametric & Wilcoxon matched-pairs signed rank test & $n=10$ mice & $p=0.9102$ \\
\hline$a b$ & Fig. $6 \mathrm{~A}$ & Two variables & $r$ and $r_{\mathrm{s}}$ & $n=10$ mice & $\begin{array}{l}r=0.2132, p=0.5543 \\
r_{\mathrm{s}}=0.1394, p=0.7072\end{array}$ \\
\hline ac & Fig. $6 \mathrm{~B}$ & Two variables & $r$ and $r_{\mathrm{s}}$ & $n=10$ mice & $\begin{array}{l}r=0.3706, p=0.2918 \\
r_{\mathrm{s}}=0.3091, p=0.3869\end{array}$ \\
\hline ad & Fig. $6 \mathrm{C}$ & Two variables & $r$ and $r_{\mathrm{s}}$ & $n=10$ mice & $\begin{array}{l}r=0.8089, p=0.0046 \\
r_{\mathrm{s}}=0.7818, p=0.0105\end{array}$ \\
\hline $\mathrm{ae}$ & Fig. $6 \mathrm{D}$ & Two variables & $r$ and $r_{\mathrm{s}}$ & $n=10$ mice & $\begin{array}{l}r=0.7793, p=0.0079 \\
r_{\mathrm{s}}=0.7091, p=0.0268\end{array}$ \\
\hline af & Fig. $6 \mathrm{E}$ & Two variables & $r$ and $r_{\mathrm{s}}$ & $n=10$ mice & $\begin{array}{l}r=0.9051, p=0.0003 \\
r_{\mathrm{s}}=0.9605, p<0.0001 \\
\text { Bonferroni's correction: } 2 \text { comparisons, } \\
\alpha=0.025\end{array}$ \\
\hline ag & Fig. $6 \mathrm{~F}$ & Two variables & $r$ and $r_{\mathrm{s}}$ & $n=10$ mice & $\begin{array}{l}r=0.7426, p=0.0139 \\
r_{\mathrm{s}}=0.7455, p=0.0174 \\
\text { Bonferroni's correction: } 2 \text { comparisons, } \\
\alpha=0.025\end{array}$ \\
\hline ah & Fig. $6 \mathrm{G}$ & Two variables & $r$ and $r_{\mathrm{s}}$ & $n=10$ mice & $\begin{array}{l}r=0.5701, p=0.0853 \\
r_{\mathrm{s}}=0.5152, p=0.1334 \\
\text { Bonferroni's correction: } 2 \text { comparisons, } \\
\alpha=0.025\end{array}$ \\
\hline ai & Fig. $6 \mathrm{H}$ & Two variables & $r$ and $r_{\mathrm{s}}$ & $n=10$ mice & $\begin{array}{l}r=0.8391, p=0.0024 \\
r_{\mathrm{s}}=0.7818, p=0.0105 \\
\text { Bonferroni's correction: } 2 \text { comparisons, } \\
\alpha=0.025\end{array}$ \\
\hline aj & Fig. 7A & Two variables & $r$ and $r_{\mathrm{s}}$ & $n=10$ mice & $\begin{array}{l}r=0.1131, p=0.7558 \\
r_{\mathrm{s}}=-0.0901, p=0.8113\end{array}$ \\
\hline ak & Fig. 7B & Two variables & $r$ and $r_{\mathrm{s}}$ & $n=10$ mice & $\begin{array}{l}r=0.1634, p=0.6520 \\
r_{\mathrm{s}}=0.2727, p=0.4483\end{array}$ \\
\hline al & Fig. $7 \mathrm{C}$ & Two variables & $r$ and $r_{\mathrm{s}}$ & $n=10$ mice & $\begin{array}{l}r=-0.1255, p=0.7297 \\
r_{\mathrm{s}}=-0.0909, p=0.8113\end{array}$ \\
\hline am & Fig. 7D & Two variables & $r$ and $r_{\mathrm{s}}$ & $n=10$ mice & $\begin{array}{l}r=-0.3601, p=0.3068 \\
r_{\mathrm{s}}=-0.3455, p=0.3304\end{array}$ \\
\hline an & Fig. 7E & Two variables & $r$ and $r_{\mathrm{s}}$ & $n=10$ mice & $\begin{array}{l}r=-0.1352, p=0.7096 \\
r_{\mathrm{s}}=0.006061, p>0.9999\end{array}$ \\
\hline ao & Fig. $7 \mathrm{~F}$ & Two variables & $r$ and $r_{\mathrm{s}}$ & $n=10$ mice & $\begin{array}{l}r=0.3674, p=0.2963 \\
r_{\mathrm{s}}=0.4061, p=0.2475\end{array}$ \\
\hline ap & Fig. $7 \mathrm{G}$ & Two variables & $r$ and $r_{\mathrm{s}}$ & $n=10$ mice & $\begin{array}{l}r=0.05994, p=0.8694 \\
r_{\mathrm{s}}=0.1394, p=0.7072\end{array}$ \\
\hline aq & Fig. $7 \mathrm{H}$ & Two variables & $r$ and $r_{\mathrm{s}}$ & $n=10$ mice & $\begin{array}{l}r=0.2834, p=0.4275 \\
r_{\mathrm{s}}=0.2485, p=0.4918\end{array}$ \\
\hline ar & Fig. $8 \mathrm{C}$ & Two variables & $r$ and $r_{\mathrm{s}}$ & $n=10$ mice & $\begin{array}{l}r=0.8011, p=0.0053 \\
r_{\mathrm{s}}=0.8909, p=0.0011\end{array}$ \\
\hline as & Fig. 8D & Two variables & $r$ and $r_{\mathrm{s}}$ & $n=10$ mice & $\begin{array}{l}r=0.4686, p=0.1719 \\
r_{\mathrm{s}}=0.5879, p=0.0806\end{array}$ \\
\hline
\end{tabular}

$=0.375)$. These results show that during short-term abstinence, cocaine-associated olfactory cues selectively increase behavioral arousal in the form of pupil dilation, but do not selectively influence locomotion.

\section{Cocaine does not alter average spontaneous and cue-evoked neural dynamics early in abstinence}

To monitor frontostriatal network dynamics in abstinent drug-conditioned animals, we developed a 512 electrode silicon microprobe enabling large-scale simultaneous recordings in the MPFC and VS (Fig. $3 A$ ). Correct electrode placement was confirmed histologically (Fig. $3 B$ ). Units in each area were classified as principal cells (pyramidal cells in the MPFC, and MSNs in the VS) or interneurons based on spike waveform width (see Materials and Methods; Fig. $3 C$ ). We recorded a total of 2063 single units from drug-treated mice and 1141 units from control mice. In drug-treated mice, $72.7 \%$ of mPFC neurons fit our criteria for being pyramidal neurons, $14.7 \%$ were putative FSIs, and $12.6 \%$ were unclassified. In drug-treated mice, $63.4 \%$ of VS neurons fit our criteria for MSNs, $18.5 \%$ were putative FSIs, $6.4 \%$ were putative TANs, and $11.7 \%$ were unclassified (Fig $3 D$ ). In control mice, $72.3 \%$ of mPFC neurons fit our criteria for being pyramidal neurons, 

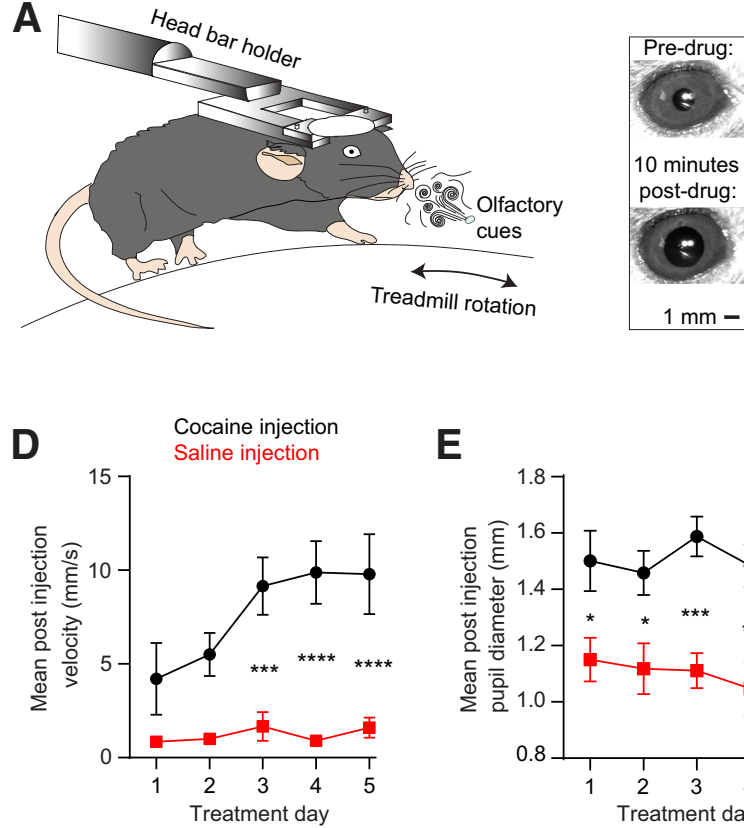

I

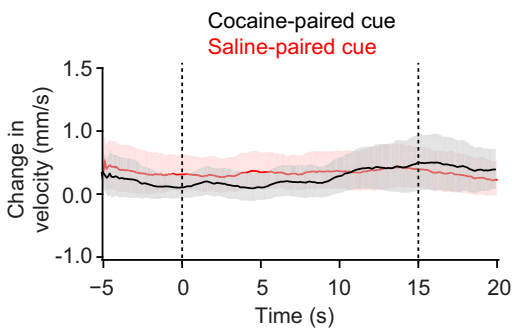

E

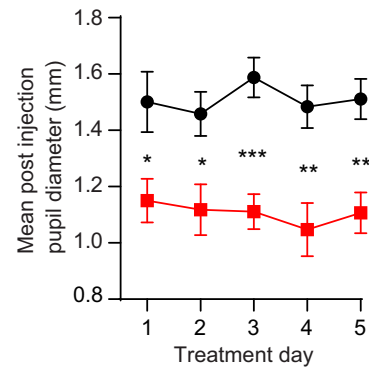

J
B

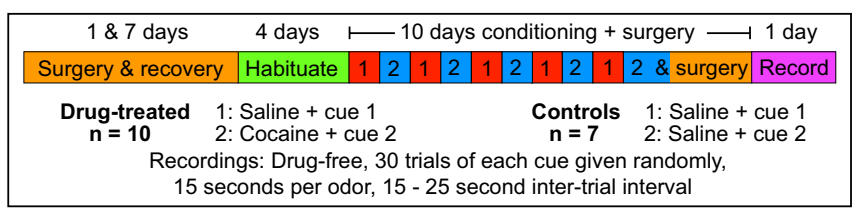

C

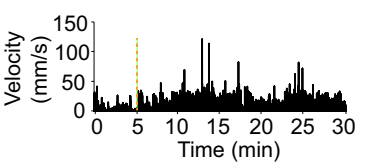

F

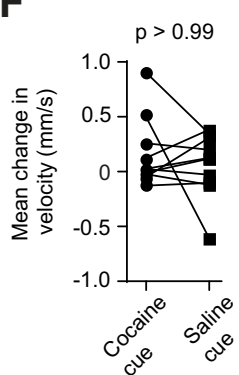

G

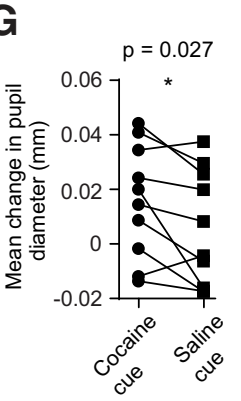

K

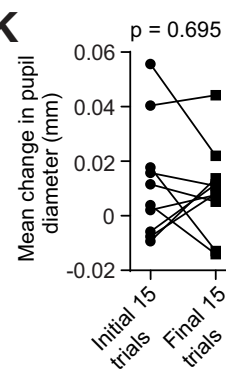

H
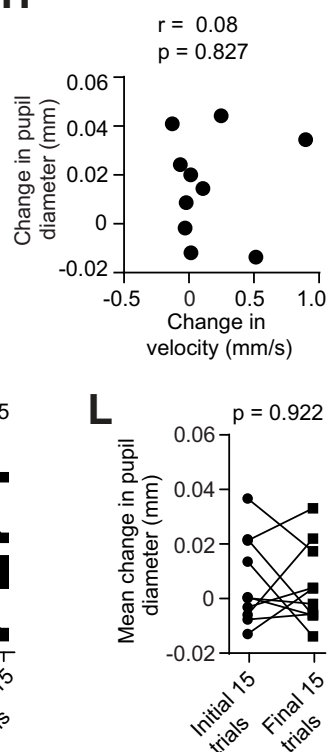

Figure 1. Enhancement of cocaine cue-evoked pupil dilation during drug abstinence. $\boldsymbol{A}$, Left, Setup for drug conditioning using olfactory cues in head-restrained mice. Behavior was monitored in the form of pupil dilation and circular treadmill rotation velocity. Right, Image of the pupil of an animal before drug injection (top) or 10 min after a single injection of cocaine during conditioning (bottom). B. Timeline of surgery, habituation, drug conditioning, and recording. $\boldsymbol{C}$, Time dependence of absolute value of treadmill rotation velocity (left) and pupil diameter (right) for one representative animal on the first day of cocaine conditioning. Dashed line indicates the time of drug injection. $\boldsymbol{D}$, For the drug group $(n=10)$, postinjection treadmill rotation velocity showed a significant effect of treatment type (two-way ANOVA, $F_{(1,18)}=31.50, p<0.0001$ ) and day of treatment $\left(F_{(4,72)}=3.75, p=0.008\right.$ ). E, Postinjection pupil diameter showed a significant effect of treatment type (two-way ANOVA, $F_{(1,18)}=17.66, p=0.0005$ ), while there was no effect of day of treatment $\left(F_{(4,72)}=0.831, p=0.510\right)$. $\boldsymbol{F}$, When presented with the cues on the test day in the absence of cocaine, drug-experienced mice $(n=10)$ showed an equal locomotor response to cocaine- and saline-associated cues (Wilcoxon matched-pairs signed rank test, $p>0.99$ ). G, Drug-experienced mice showed a higher pupil dilation in response to cocaine-associated cues (Wilcoxon matched-pairs signed rank test, $p=0.027)$. $\boldsymbol{H}$, Cocaine cue-mediated pupil dilation changes were not correlated with treadmill rotation changes $(r=0.08, p=0.827)$. $\boldsymbol{I}$, Cue-triggered treadmill rotation velocity vs time averaged across drug-treated mice shows no difference in locomotion between cocaine- and saline-paired cues. Dashed lines indicate cue onset and offset. $\boldsymbol{J}$, Mean cue-triggered change in pupil dilation vs time. Blue lines indicate time bins where the cocaine and saline cues elicited significantly different dilation (paired $t$ test, $p<0.05$ ). $\boldsymbol{K}$, There was no significant difference in pupillary response between the initial 15 trials and final 15 trials of the cocaine cue (Wilcoxon matched pairs signed-rank test, $p=0.695$ ). $L$, There was no significant difference in pupillary response between the initial 15 trials and the final 15 trials of the saline cue (Wilcoxon matched pairs signed-rank test, $p=$ 0.922). Data in $\boldsymbol{D}, \boldsymbol{E}, \boldsymbol{I}$, and $\boldsymbol{J}$ are reported as the mean \pm SEM. $* p<0.05, * * p<0.01, * * * p<0.001, * * * * p<0.0001$.

$10.5 \%$ were putative FSIs, and $17.2 \%$ were unclassified. In control mice, $60 \%$ of VS neurons fit our criteria for MSNs, $20.8 \%$ were putative FSIs, $7.2 \%$ were putative TANs, and $12 \%$ were unclassified.

Cocaine exposure is frequently associated with prefrontal hypoactivity (Trantham et al., 2002; Chen et al., 2013). Furthermore, the prelimbic and infralimbic regions of the mPFC are often associated with opposing roles in cocaine-seeking behavior (Peters et al., 2008). To exam- ine spontaneous firing properties in these subregions, we selected units from the top and bottom halves of the electrode array (Fig. $4 A$, cortex, $B$, striatum), and compared the mean spontaneous firing rate per animal of different neuronal populations between the drug and control groups. After correcting for two comparisons, we did not find a significant difference in the spontaneous firing rate of cocaine-treated animals in any of the cortical and striatal subregions examined (Fig. 4C-F; Mann-Whitney $U$ 
A

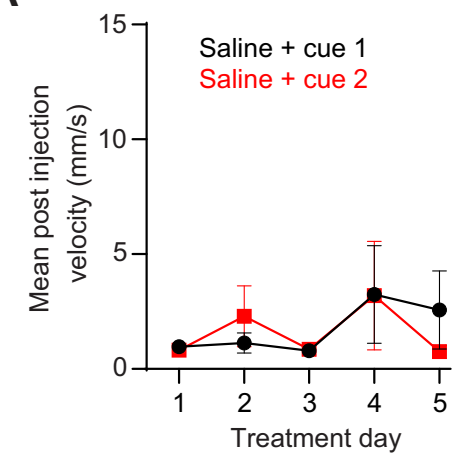

C

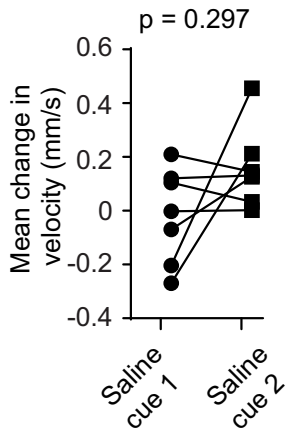

B

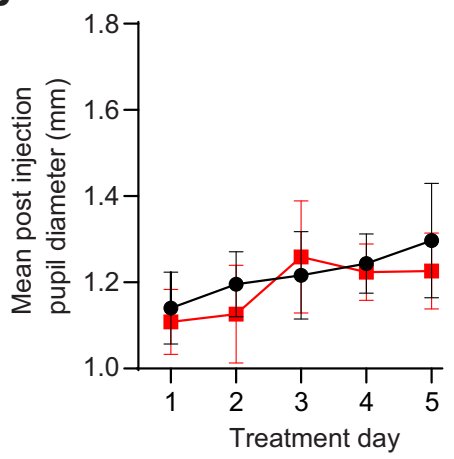

D

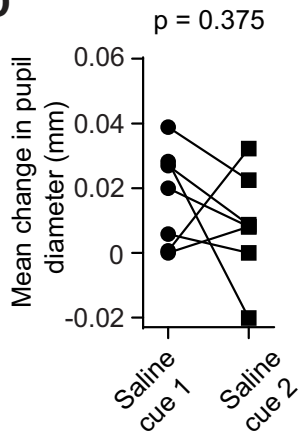

Figure 2. Control mice do not show differences in cue-evoked pupil dilation. $\boldsymbol{A}$, For the control group $(n=7)$, postinjection treadmill rotation velocity showed no effect of odor type (two-way ANOVA, $F_{(1,12)}=0.024, p=0.878$ ) or day of treatment $\left(F_{(4,48)}=1.450, p\right.$ $=0.232)$. $\boldsymbol{B}$, Control group animals showed no effect of odor type $\left(F_{(1,12)}=0.072, p=0.794\right)$ or day of treatment $\left(F_{(4,48)}=1.777, p\right.$ $=0.149)$. $C$, When presented with cues on the test day, control group mice $(n=7)$ showed an equal locomotor response to both cues (Wilcoxon matched-pairs signed rank test, $p=0.297$ ). $\boldsymbol{D}$, When presented with cues on the test day, control group mice showed an equal pupillary response to both cues (Wilcoxon matched-pairs signed rank test, $p=0.375$ ). Data in $\boldsymbol{A}$ and $\boldsymbol{B}$ are reported as the mean \pm SEM.

test, $p>0.025$, none of the results are significant after adjusting $\alpha$ to 0.025 following Bonferroni's multiple comparisons correction). When comparing the mean spontaneous rate per animal, the relatively small number $(n=$ 3-5) of FSls recorded in certain subregions of some animals may have contributed to the large variability of our FSI results, making it challenging to detect an effect of cocaine. Therefore, we also performed a comparison after pooling all FSIs in the drug and control groups. Again, we found no significant difference in firing rate between these groups (Fig. 4G,H; Kolmogorov-Smirnov test, $p>0.05$ ). These results demonstrate that for the areas targeted with our electrodes, cocaine does not significantly alter the spontaneous cortical or striatal activity of principal neurons and FSls early in abstinence.

We next examined cue-evoked neural activity. A portion of principal neurons in the MPFC and VS showed significant excitation or inhibition in response to cocaineassociated olfactory stimuli (Fig. $5 A-D$ ), demonstrating that neural activity is modulated by olfactory cues. However, there was no difference in the fraction of neurons that was excited or inhibited by cocaine versus saline cues (Fig. $5 E-H$; all $p>0.05$, paired Wilcoxon signed-rank test). These results show that, on average, these circuits do not appear to preferentially encode cocaine-associated cues.

\section{Conditioned pupillary response correlates with frontostriatal inhibition}

Since we did not find differences in the mean level of cocaine- and saline-associated cue encoding in the MPFC and VS, we next tested whether the variability in behavioral responses among individual drug-experienced animals $(n=10)$ could account for the observed patterns of neural activity. Since drug-paired cues selectively affected pupillary responses, but not treadmill locomotion, we focused on individual animal changes in pupil diameter in response to cocaine cue presentation. We found that the mean change in pupil diameter was unrelated to the fraction of significantly excited pyramidal neurons (Fig. $6 A, r=0.213, p=0.554$ ) and MSNs (Fig. $6 B, r=$ $0.371, p=0.292)$. In contrast, there was a significant positive correlation between pupil diameter change and the fraction of inhibited pyramidal neurons (Fig. 6C, $r=$ $0.809, p=0.005$ ) and MSNs (Fig. $6 D, r=0.779, p=$ 0.008 ). These results were obtained by combining units from all electrode depths in the MPFC and VS. To examine whether these relationships are consistent within different cortical and striatal subregions, in each area we partitioned units into two groups according to their location on the electrode, as previously described (see Materials and Methods; Fig. $4 A, B$ ). In the mPFC, the fraction of inhibited units in both the top and bottom halves of the 
A

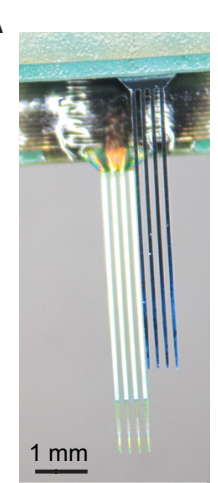

B
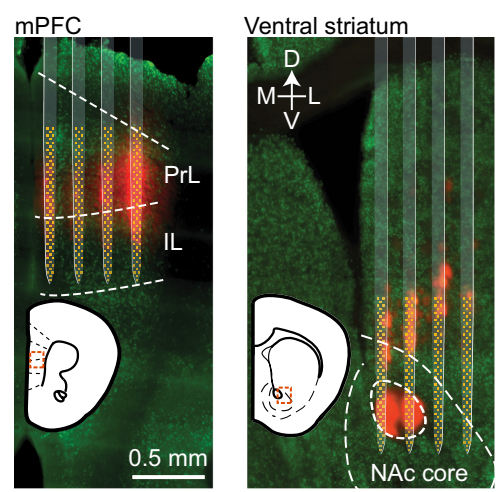

C
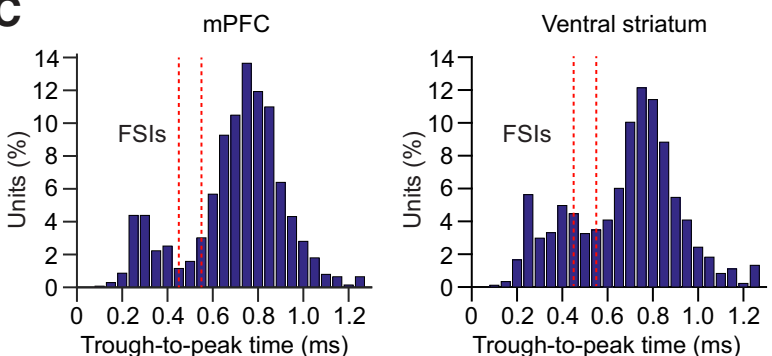

D

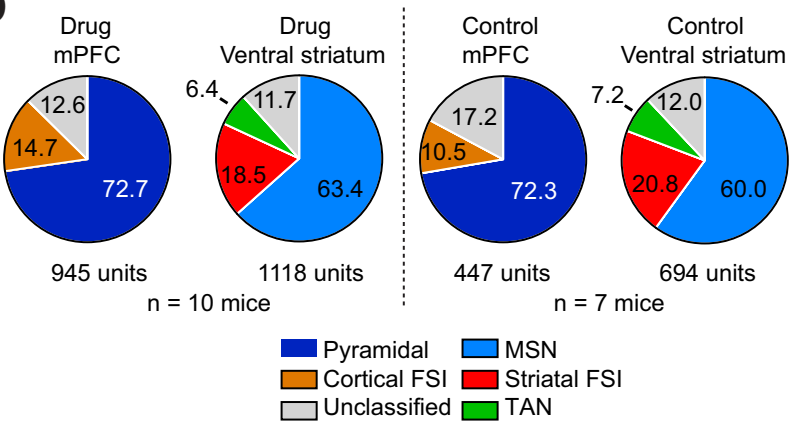

Figure 3. Large-scale neural recordings in the frontostriatal circuit. $\boldsymbol{A}$, A 512 electrode silicon microprobe targeting the mPFC and VS. $\boldsymbol{B}$, Representative reconstruction of electrode placement in the mPFC (left) and VS (right) from the same animal. Red, DiD dye; green, NeuN staining. $\boldsymbol{C}$, Distribution of trough-to-peak spike duration in the MPFC and VS. Red dashed lines denote the classification boundary between $\mathrm{FSI}$ and non-FSI units (units between the lines are unclassified). $\boldsymbol{D}$, Proportion and total number of cells recorded in the MPFC and VS in the drug and control groups.

electrode array, corresponding approximately to the prelimbic and infralimbic cortex, maintained a relationship between the fraction of inhibited cells and the change in pupil diameter (Fig. $6 E, r=0.905, p=0.0003$; Fig. $6 F, r=$ $0.743, p=0.014)$. In the VS, the fraction of units recorded from the top half of electrodes (corresponding to the medial striatum) showed no correlation to behavior (Fig. $6 G, r=0.571, p=0.085)$, whereas the fraction of units from the bottom half (corresponding to the nucleus accumbens core) inhibited by the drug cue remained highly correlated to pupillary response (Fig. $6 H, r=0.839, p=$ 0.002 ). These results suggest that during early drug abstinence, inhibition of the medial prefrontal cortex and the nucleus accumbens core is involved in conditioned arousal to drug-associated cues. In contrast, medial striatal MSNs do not appear to have such a relationship with behavior.

We next looked for correlations between the fraction of excited or inhibited cells, and treadmill running evoked by cocaine-paired cues. There was no significant correlation (Fig. $7 A-D, p>0.05$; exact probability values are in the figure legend), suggesting that frontostriatal activity is more related to conditioned arousal in the form of pupil dilation than it is to conditioned locomotion.

To determine whether neural activity has any relationship with saline cue-evoked pupil dilation, we also looked for correlations between the fraction of excited or inhibited cells and pupil dilation in response to saline-paired cues. There was no statistically significant correlation in any of these comparisons (Fig. $7 E-H, p>0.05$ ). Thus, while we found significant correlations between cocaine cue-evoked frontostriatal inhibition and pupil dilation, there was no corresponding relationship of saline cueevoked activity with pupil dilation. This is consistent with brain circuit alterations following drug exposure that selectively mediate conditioned arousal responses to drugassociated stimuli, but not neutral stimuli.

\section{Conditioned pupillary response correlates with frontostriatal LFP coherence}

Since the mPFC projects to the VS (Berendse et al., 1992; Voorn et al., 2004), neural activity in these areas is related (Chang et al., 2000; Ishikawa et al., 2008). To gain insight into the significance of this interaction for our behavioral task, we examined whether neural synchrony in the form of LFP coherence was related to cue-evoked arousal measured via pupillary responses. LFP signals were measured together with single-unit action potentials on the same electrodes. Frontostriatal LFP coherence spectra revealed a peak in coupling between the $\mathrm{MPFC}$ and VS at $\sim 25-45 \mathrm{~Hz}$ both under resting conditions (Fig. $8 A$ ) and during cocaine cue presentations (Fig. 8B). These rhythms are within the frequency range of LFP signals that were previously found to be sensitive to cocaine administration (McCracken and Grace, 2013). Across the animals tested in the drug group $(n=10)$, we found a significant correlation between the mean change in cocaine cue-evoked 25-45 Hz coherence and pupil diameter (Fig. 8C, $r=$ $0.801, p=0.005)$. This relationship held even after partitioning LFP signals from the top and bottom half of the electrode array in each area (results not shown; $p<$ 0.025 , all correlations remain significant after adjusting $\alpha$ to 0.025 following Bonferroni's correction for two comparisons). Finally, we did not find an analogous relationship between the change in saline cue-evoked LFP coherence and pupil diameter (Fig. $8 D, r=0.467, p=$ $0.172)$. As shown in Figure $7 E-H$, this is consistent with a conditioned arousal response to drug-associated stimuli, but not neutral stimuli.

\section{Discussion}

This study introduced an assay of behavioral responses to cocaine-associated olfactory stimuli, which was specifically developed to support large-scale electrophysiological recordings in awake head-restrained mice. The assay 
A

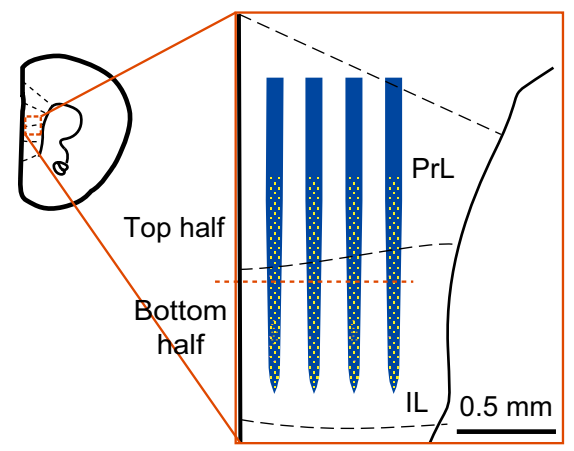

B

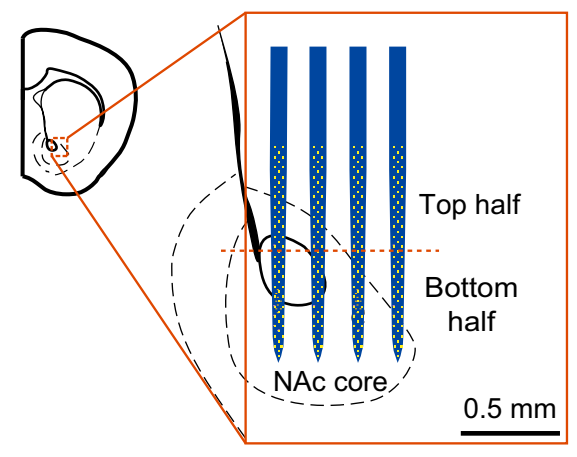

C

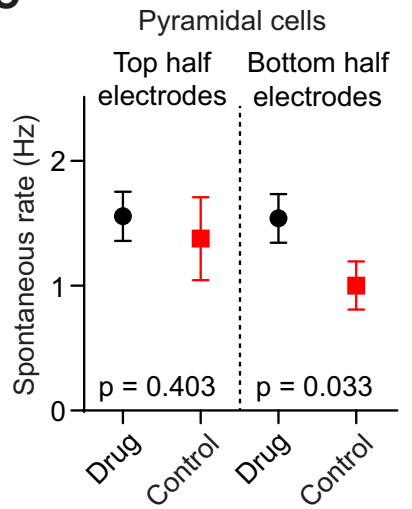

E

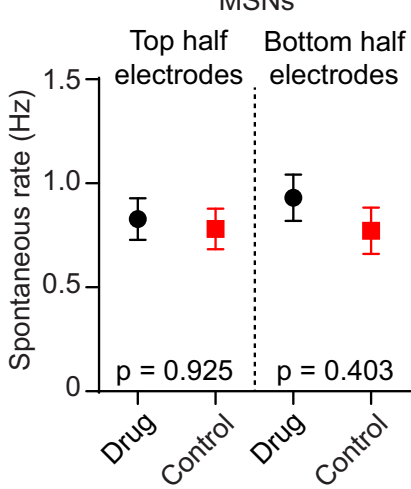

D

Cortical FSIs

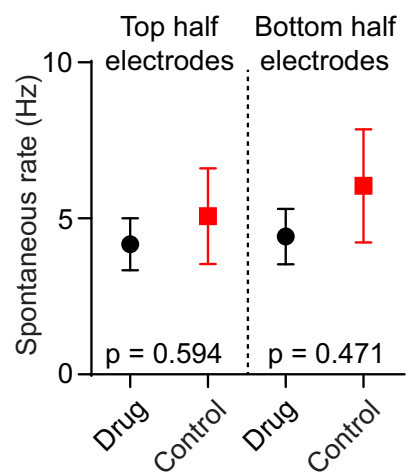

F

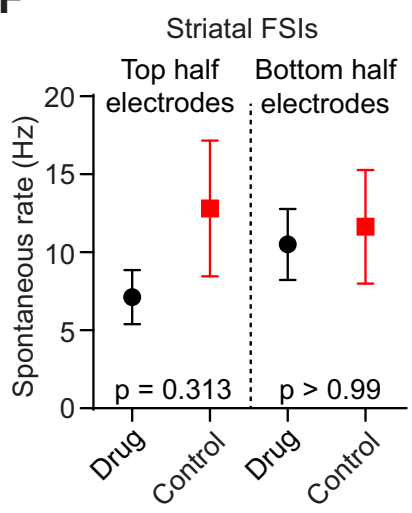

G

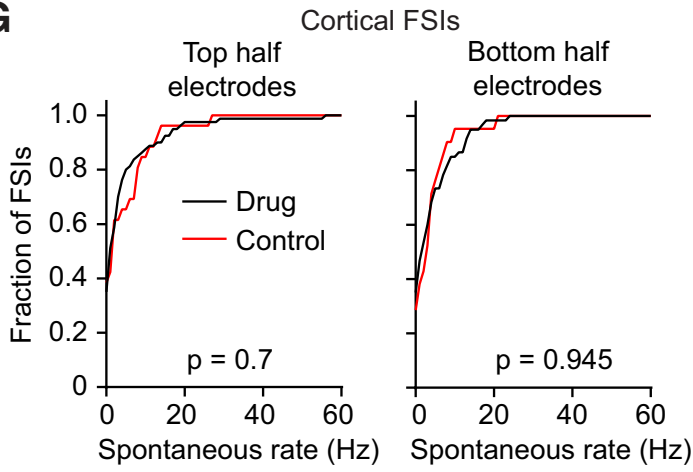

H

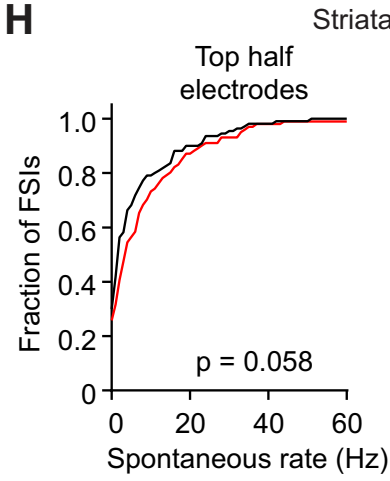

Bottom half electrodes

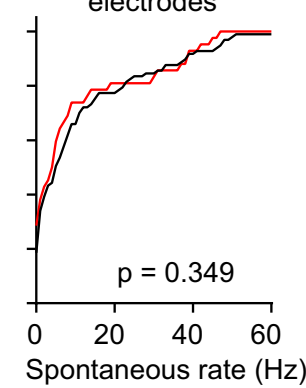

Figure 4. Cocaine does not alter spontaneous cortical or striatal firing rate in early abstinence. $\boldsymbol{A}, \boldsymbol{B}$, Illustration of how units in the mPFC and VS were partitioned according to their location on the top or bottom half of the electrode array. $\boldsymbol{C}-\boldsymbol{F}$, There was no difference between the average firing rate of principal cells or FSIs in any of the subregions examined (Mann-Whitney $U$ test, $p>$ 0.025; exact probability values are listed in the figure, $\alpha$ was adjusted to 0.025 after Bonferroni's correction for two comparisons, corresponding to the top and bottom partitions). Data in $\boldsymbol{C}-\boldsymbol{F}$ are reported as the mean \pm SEM firing rate across the animals in the drug $(n=10)$ and control $(n=7)$ groups. $\mathbf{G}, \boldsymbol{H}$, There was no difference in the pooled spontaneous FSI firing rate in any of the subregions examined (Kolmogorov-Smirnov test, $p>0.05$; exact probability values are listed in the figure).

used measurements of pupil dilation and treadmill movement. Pupillary response is an autonomic behavior that is modulated by the state of arousal of an animal (Hess and Polt, 1960; Bradley et al., 2008; Vinck et al., 2015). Pupil dilation is influenced by locomotion but can also be modulated independent of movement (Vinck et al., 2015), providing two related but separable approaches for tracking how mice respond to cocaine injection or cocaineassociated cues. Specifically, as drug conditioning progressed animals responded to cocaine injections with increased locomotion on a circular treadmill, consistent with a psychomotor sensitization effect (Robinson and Berridge, 2008). Pupil dilation was also impacted by cocaine administration, but this response did not change significantly as drug conditioning progressed, which may reflect a ceiling effect after just the first injection. After a $24 \mathrm{~h}$ drug abstinence period, there was greater pupil dilation in response to odors previously paired with co- 
A

A Pyramidal cells excited by cue

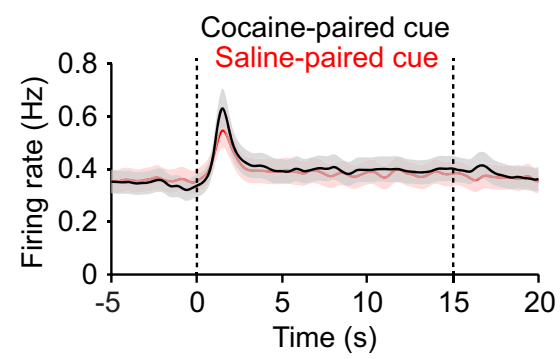

C

Pyramidal cells inhibited by cue

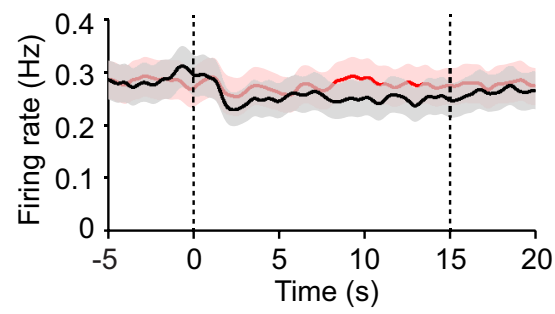

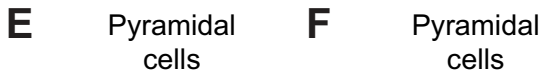

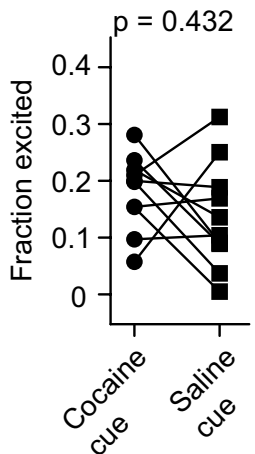

B

MSNs excited by cue

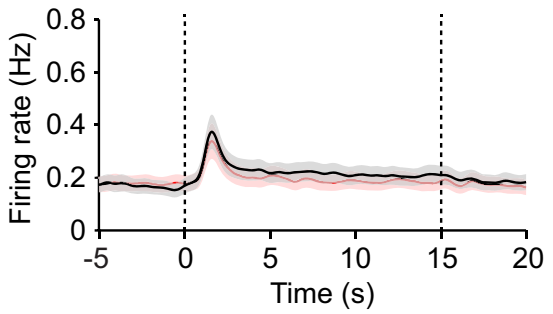

MSNs inhibited by cue

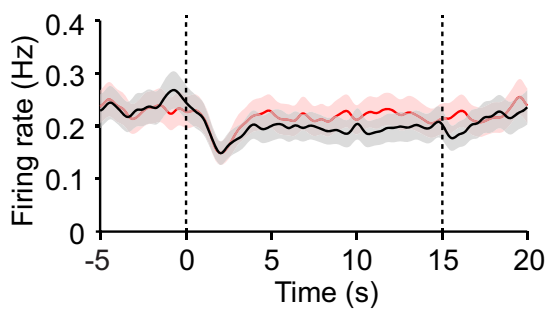

G MSNs $\quad \mathbf{H} \quad$ MSNs

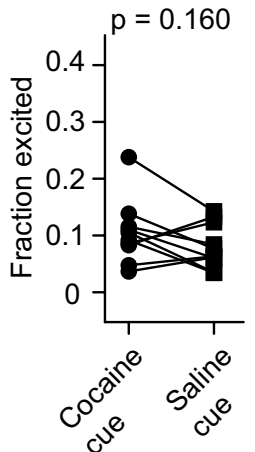

Figure 5. Average cue-evoked activity is not selective for cocaine-associated stimuli. $\boldsymbol{A}, \boldsymbol{B}$, Mean cue-triggered firing rate of all significantly excited pyramidal cells and MSNs, combined across data from the drug treatment group. Black and red lines, respectively, indicate the response to cocaine- and saline-paired cues. Dashed lines indicate cue onset and offset. There was no significant difference between the response to cocaine- and saline-paired cues at any time point (paired permutation test, $p>0.05$ ). $\boldsymbol{C}, \boldsymbol{D}$, Mean cue-triggered firing rate of all significantly inhibited pyramidal cells and MSNs, combined across data from the drug treatment group. There was no significant difference between the response to cocaine- and saline-paired cues at any time point (paired permutation test, $p>0.01$ ). Data in $\boldsymbol{A}-\boldsymbol{D}$ are reported as the mean \pm SEM. $\boldsymbol{E}, \boldsymbol{F}$, There was no difference in the average fraction of cortical pyramidal cells excited or inhibited by cocaine cues (Wilcoxon matched pairs signed-rank test, $p>0.05$ ). $\boldsymbol{G}, \boldsymbol{H}$, There was no difference in the average fraction of MSNs excited or inhibited by cocaine cues (Wilcoxon matched pairs signed-rank test, $p>$ 0.05). Data in $\boldsymbol{E}-\boldsymbol{H}$ denote the fraction of cells per animal in the drug group $(n=10)$.

caine than with saline, whereas there was no difference in locomotion on the treadmill. This demonstrates that under the conditions of our behavioral test, pupillary response is more sensitive to cocaine cues than locomotion, at least in the early stage of drug abstinence. The most parsimonious interpretation of these results is that animals are more aroused by odors previously paired with cocaine because of an associative learning process that occurred during the conditioning period (O'Brien et al., 1998). We therefore presume that interindividual variations in the amplitude of the pupil dilation effect reflect differences in conditioned arousal. An open question of this study is whether cue-evoked pupil dilation is related to elevated drug craving. Analogous effects have been shown in studies with addicted human subjects using other autonomic responses (heart rate and skin conductance; Ehrman et al., 1992). Thus, while we cannot be certain that the mice in this study craved drugs, the conditioned arousal response appears to be consistent with elevated craving.

To the best of our knowledge, our study is the first use of pupillometry to assess responses to drug-paired cues in mice. The rapid occurrence of the dilation effect (within $24 \mathrm{~h}$ after the last drug administration) presents a sensitive, noninvasive method to measure drug cue arousal in 
A

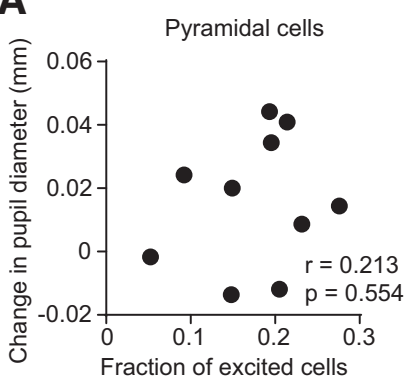

E

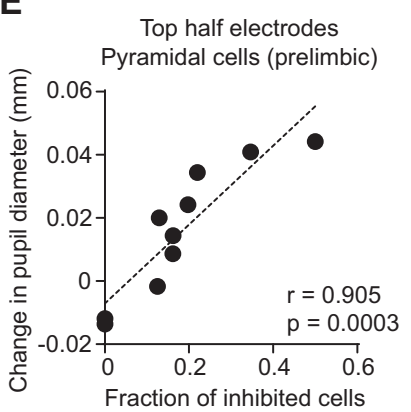

B

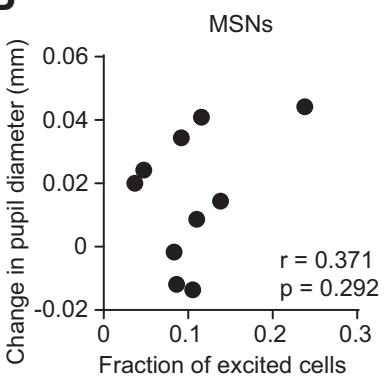

F

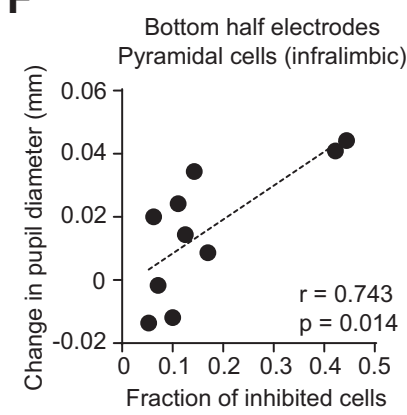

C

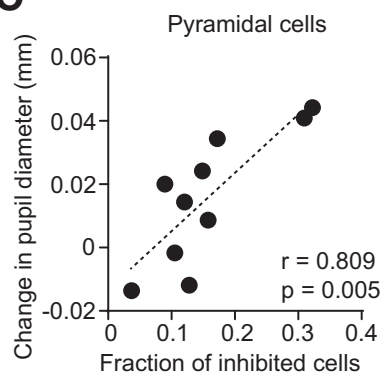

G

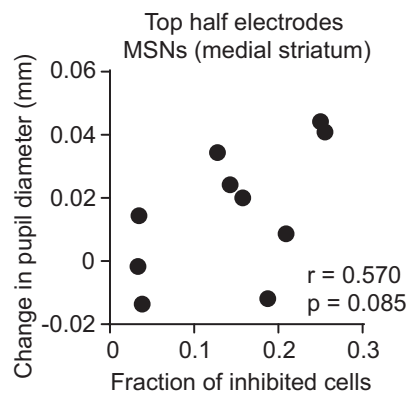

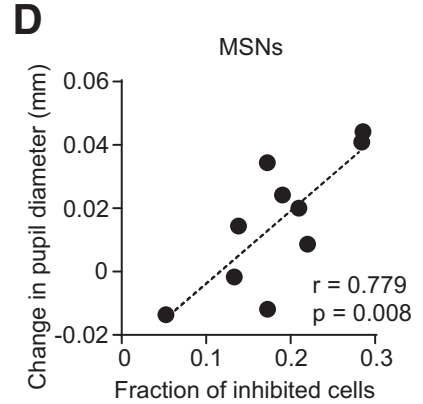

H

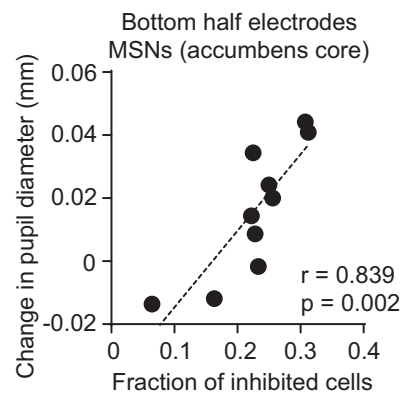

Figure 6. Cocaine cue-evoked pupil dilation correlates with frontostriatal inhibition. $\boldsymbol{A}$, There was no correlation of mean change in pupillary response to the fraction of cortical pyramidal neurons excited by the cocaine-paired cue $(r=0.213, p=0.554)$. $\boldsymbol{B}$, There was no correlation of mean change in pupillary response to the fraction of MSNs excited by the cocaine-paired cue $(r=0.371, p=$ 0.292). $\boldsymbol{C}$, The mean change in pupillary response was correlated with the fraction of inhibited pyramidal neurons $(r=0.809, p=$ 0.005). $\boldsymbol{D}$, The mean change in pupillary response was correlated with the fraction of inhibited MSNs $(r=0.779, p=0.008)$. Results from $\boldsymbol{A}-\boldsymbol{D}$ were obtained by combining cortical or striatal principal cells across the entire electrode array. $\boldsymbol{E}, \boldsymbol{F}$, Inhibited units in both the prelimbic and infralimbic cortex maintained their relationship to pupillary response (Pearson's correlation, $p<0.025 ; \alpha$ was adjusted to 0.025 after Bonferroni's correction for two comparisons; exact probability values are listed in the figure). $\mathbf{G}$, Inhibited MSNs in the medial striatum were uncorrelated to pupillary response $(r=0.570, p=0.085)$. $\boldsymbol{H}$, Inhibited MSNs in the nucleus accumbens core were correlated with pupillary response $(r=0.839, p=0.002)$. Plots show data from the drug group $(n=10)$.

models of addiction. Furthermore, since pupillometry is compatible with neuroimaging methods in human subjects (Bray et al., 2008), the task introduced here has potentially useful applications in human addiction research and diagnosis.

We combined this behavioral assay with silicon microprobe technology to simultaneously record from dozens of electrophysiologically identified prefrontal and striatal units. We initially focused on differences in spontaneous neural activity between drug- and control-treated mice 24 $\mathrm{h}$ after the last cocaine injection. We found that spontaneous activity in the areas examined was unaltered. Cocaine use frequently has been associated with prefrontal hypoactivity (Jentsch and Taylor, 1999; Trantham et al., 2002; Sun and Rebec, 2006; Chen et al., 2013). From our data, we infer that hypoactivity is not a strong feature of the circuits we examined in the first $24 \mathrm{~h}$ of cocaine abstinence. In fact, we even noted a tentative trend toward higher pyramidal cell firing in the infralimbic portion of the PFC (Fig. 4C; Mann-Whitney $U$ test, $p=0.033$, which is not significant after adjusting $\alpha$ to 0.025 following Bonferroni's correction for two comparisons), suggesting that short-term and long-term states of abstinence may be characterized by different states of resting brain activity. An additional consideration is that the electrophysiological recordings and spike sorting are inherently biased toward more spontaneously active neurons. Thus, it is possible that this analysis did not take into account relatively silent units.

We also examined cue-evoked neural activity, focusing on units with significant excitatory or inhibitory responses. Our results show that, on average, cocaine and saline cue-evoked frontostriatal network dynamics were not discernibly different in the early stage of drug abstinence. Previous studies suggest a somewhat complex activation pattern involving a mixture of enhanced and reduced activity in prefrontal and striatal networks by drugassociated cues (Ghitza et al., 2003; Goldstein and Volkow, 2011; Mahler and Aston-Jones, 2012; West et al., 2014). Several factors may contribute to our observed level of cue-modulated neural activity in the frontostriatal network. The first consideration is that the relatively short duration of abstinence in our study (24 h) does not induce significant incubation effects (Pickens et al., 2011). An increase in cue-evoked VS neural firing has been observed after extended (30 d) periods of abstinence (Hollander and Carelli, 2007; West et al., 2014). A second factor may be that the recording sites in the VS targeted regions that do not discriminately encode cocaine from neutral cues (Ghitza et al., 2003).

While neither the mPFC nor the VS selectively encoded cocaine cues on average, we noticed a substantial vari- 
A
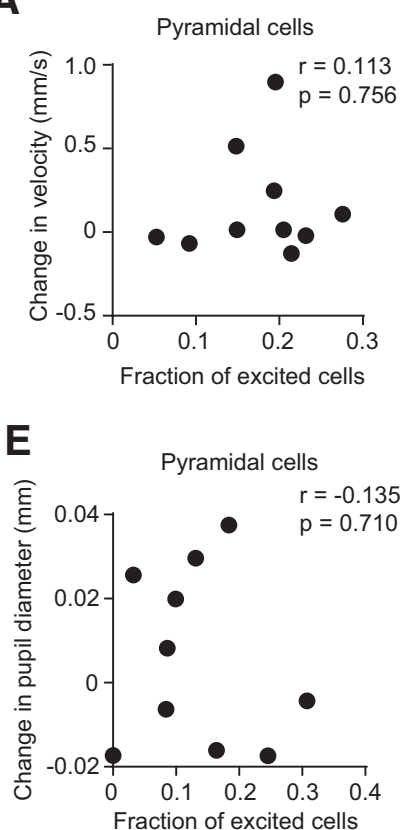

B

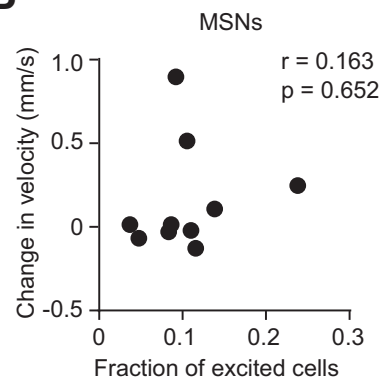

F

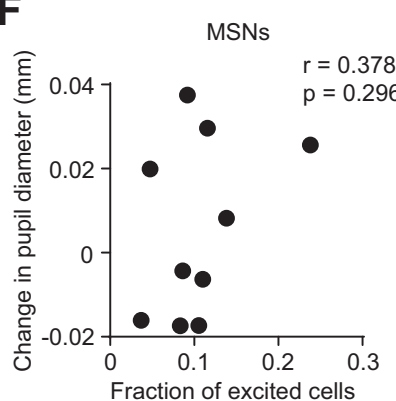

C

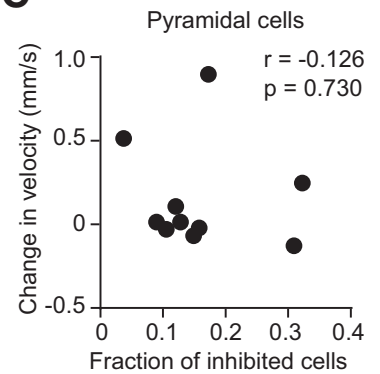

G

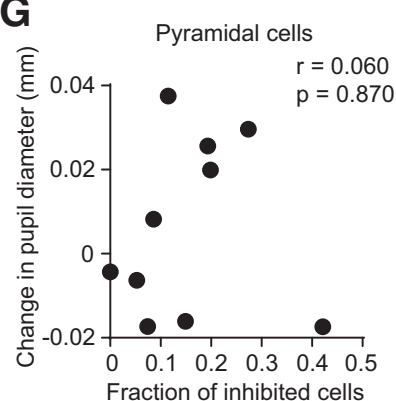

D
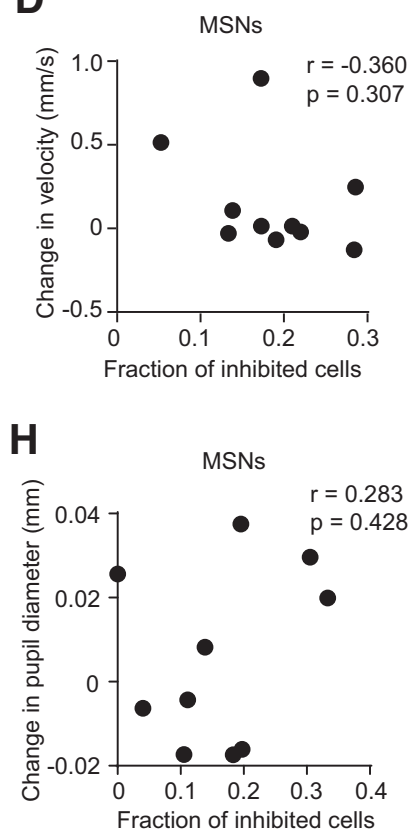

Figure 7. No correlation of neural activity with cocaine cue-evoked treadmill speed or saline cue-evoked pupil dilation. $\boldsymbol{A}$, There was no correlation of the mean change in treadmill velocity with the fraction of cortical pyramidal neurons excited by the cocaine-paired cue $(r=0.113, p=0.756)$. $\boldsymbol{B}$, There was no correlation of the mean change in treadmill velocity with the fraction of MSNs excited by the cocaine-paired cue $(r=0.163, p=0.652)$. $C$, There was no correlation of the mean change in treadmill velocity with the fraction of cortical pyramidal neurons inhibited by the cocaine-paired cue $(r=-0.126, p=0.73)$. $\boldsymbol{D}$, There was no correlation of the mean change in treadmill velocity with the fraction of MSNs inhibited by the cocaine-paired cue $(r=-0.36, p=0.307)$. $\boldsymbol{E}$, There was no correlation of the mean change in pupillary response with the fraction of cortical pyramidal neurons excited by the saline-paired cue $(r=-0.135, p=0.701)$. $\boldsymbol{F}$. There was no correlation of the mean change in pupillary response with the fraction of MSNs excited by the saline-paired cue $(r=0.367, p=0.296)$. $G$, There was no correlation of the mean change in pupillary response with the fraction of cortical pyramidal neurons inhibited by the saline-paired cue $(r=0.060, p=0.869)$. $\boldsymbol{H}$, There was no correlation of the mean change in pupillary response with the fraction of MSNs inhibited by the saline-paired cue $(r=0.283, p=0.428)$. Results from $\boldsymbol{A}-\boldsymbol{H}$ were obtained by combining cortical or striatal principal cells across the entire electrode array. Plots show data from the drug group $(n=$ 10).

ability in the neural response between individual animals. We therefore tested whether these results could be explained by variations in the behavioral responses of individual animals. We found that changes in pupil diameter in response to cocaine-paired odors were significantly correlated with the overall fraction of inhibited principal cells in the mPFC (including both prelimbic and infralimbic areas) and the nucleus accumbens core. At the same time, we found that the fraction of excited units was not predictive of behavior. These results show that inactivation (or active suppression) of medial prefrontal and ventral striatal output is related to an elevated autonomic response to cocaine-paired stimuli.

Noradrenergic signaling from the locus ceruleus is strongly implicated in behavioral arousal (Aston-Jones and Cohen, 2005). The locus ceruleus is reciprocally connected with the cortex (Chandler et al., 2014; Schwarz et al., 2015), providing a possible route for mediating the observed relationship between pupil diameter and neural activity. The potential importance of these reciprocal interactions is supported by findings of prefrontal modulation of locus ceruleus activity (Sara and Hervé-Minvielle, 1995; Jodo et al., 1998), and electrophysiological studies showing relationships between cortical dynamics and pupil dilation (Reimer et al., 2014; McGinley et al., 2015; Vinck et al., 2015; Joshi et al., 2016). In addition to noradrenergic input, frontostriatal circuits are likely to be modulated by dopaminergic signaling (Everitt and Robbins, 2005; Goldstein and Volkow, 2011).

It is worth noting that neural inhibition in both the prelimbic and infralimbic aspects of the mPFC exhibited a significant relationship with pupil dilation. This suggests that the suppression of activity in these regions is linked to higher levels of arousal in response to cocaine cues. This finding may appear to be at odds with studies showing opposing roles for these regions in cocaine seeking, with the prelimbic and infralimbic cortex, respectively, driving and suppressing this behavior (Peters et al., 2008; LaLumiere et al., 2010). On the other hand, there is also evidence of a less dichotomous role of these regions in drug- and natural reward-related behavior (Moorman and Aston-Jones, 2015; Moorman et al., 2015). Furthermore, it is possible that, due to the considerable functional diversity of the prefrontal cortex (Fuster, 2001; Pessoa, 2008), this circuit differentially controls autonomic and voluntary responses to drug-associated cues. 
A

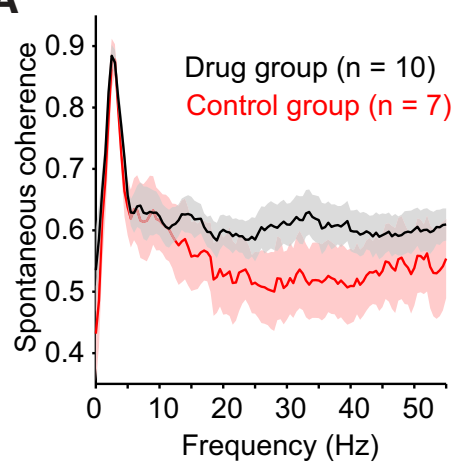

C

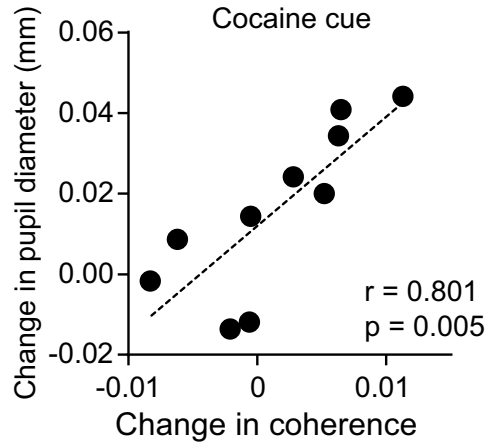

B

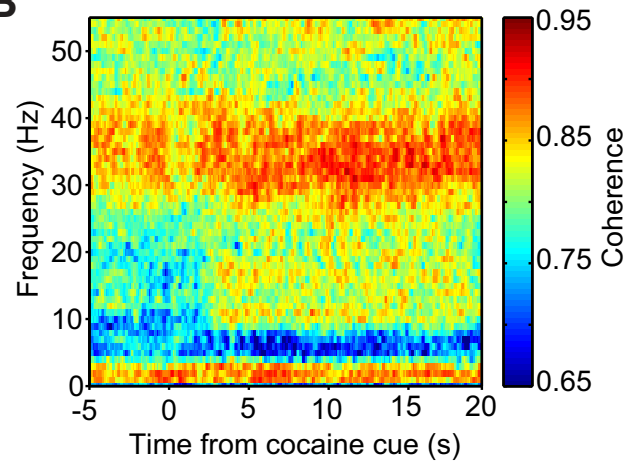

D

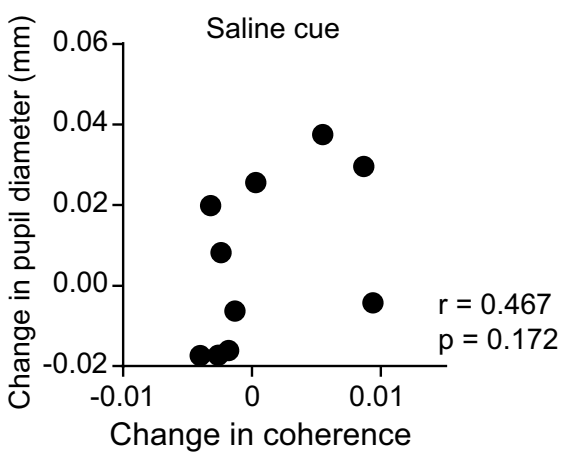

Figure 8. Cocaine cue-evoked pupil dilation correlates with $25-45 \mathrm{~Hz}$ frontostriatal LFP coherence. A, Frontostriatal coherence spectra of spontaneous LFP activity. Black and red lines, respectively, indicate the mean \pm SEM of spectra recorded from animals in the drug $(n=10)$ and control $(n=7)$ groups. Note the peak at $\sim 25-45 \mathrm{~Hz}$ for the cocaine group. $\boldsymbol{B}$, LFP coherence spectrogram from one animal showing modulation of coherence by olfactory stimuli. Data are aligned to cocaine cue onset. $\boldsymbol{C}$, The mean change in pupillary response was correlated with the change in 25-45 Hz LFP coherence during the presentation of cocaine cues $(r=0.801$, $p=0.005)$. $\boldsymbol{D}$, The mean change in pupillary response was uncorrelated with the change in $25-45 \mathrm{~Hz}$ LFP coherence during the presentation of saline cues $(r=0.467, p=0.172)$.

The mPFC projects to the VS (Berendse et al., 1992), which in turn can indirectly influence cortical activity via mesocorticolimbic feedback loops (Everitt and Robbins, 2005). We observed coherent LFP oscillations between the MPFC and VS, which are thought to synchronize VS activity to afferent signals from the mPFC (McCracken and Grace, 2013). The strength of this coherence in the $25-45 \mathrm{~Hz}$ frequency band was found to be correlated with the degree of cocaine cue-evoked pupil dilation, suggesting that the observed neural dynamics in the MPFC and VS were related to frontostriatal network interactions.

Together, this study used large-scale neural recordings in mice to examine neurophysiological properties related to drug abstinence. The high throughput of these measurements combined with a novel behavioral assay of cocaine cue arousal, enabled us to identify new relationships between frontostriatal network dynamics and behavioral responses to cocaine-associated stimuli. Our finding that cue-evoked pupil dilation is related to lower activity in the MPFC and VS, as well as increased LFP coherence between these structures, may provide new insights for understanding and preventing drug relapse. These results also highlight the importance of accounting for interindividual behavioral variability in studies of addiction, which can be significant (Groman et al., 2012;
Chen et al., 2013; Muñoz-Cuevas et al., 2013; Storey et al., 2016). Finally, the compatibility of our behavioral task with awake head-restrained mice creates new opportunities for studying systems-level neural dynamics in rodent models of addiction using a variety of complementary recording and brain circuit dissection tools.

\section{References}

Aston-Jones G, Cohen JD (2005) An integrative theory of locus coeruleus-norepinephrine function: adaptive gain and optimal performance. Annu Rev Neurosci 28:403-450. CrossRef Medline[TQ1]

Bakhurin KI, Mac V, Golshani P, Masmanidis SC (2016) Temporal correlations among functionally specialized striatal neural ensembles in reward-conditioned mice. J Neurophysiol 115:1521-1532. CrossRef Medline

Barthó P, Hirase H, Monconduit L, Zugaro M, Harris KD, Buzsáki G (2004) Characterization of neocortical principal cells and interneurons by network interactions and extracellular features. J Neurophysiol 92:600-608. CrossRef Medline

Berendse HW, Galis-de Graaf Y, Groenewegen HJ (1992) Topographical organization and relationship with ventral striatal compartments of prefrontal corticostriatal projections in the rat. $J$ Comp Neur 316:314-347. CrossRef

Bonson KR, Grant SJ, Contoreggi CS, Links JM, Metcalfe J, Weyl HL, Kurian V, Ernst M, London ED (2002) Neural systems and 
cue-induced cocaine craving. Neuropsychopharmacology 26: 376-386. CrossRef Medline

Bradley MM, Miccoli L, Escrig MA, Lang PJ (2008) The pupil as a measure of emotional arousal and autonomic activation. Psychophysiology 45:602-607. CrossRef Medline

Bray S, Rangel A, Shimojo S, Balleine B, O'Doherty JP (2008) The neural mechanisms underlying the influence of pavlovian cues on human decision making. J Neurosci 28:5861-5866. CrossRef Medline

Britt JP, Benaliouad F, McDevitt RA, Stuber GD, Wise RA, Bonci A (2012) Synaptic and behavioral profile of multiple glutamatergic inputs to the nucleus accumbens. Neuron 76:790-803. CrossRef Medline

Carelli RM, King VC, Hampson RE, Deadwyler SA (1993) Firing patterns of nucleus accumbens neurons during cocaine selfadministration in rats. Brain Res 626:14-22. Medline

Chandler DJ, Gao WJ, Waterhouse BD (2014) Heterogeneous organization of the locus coeruleus projections to prefrontal and motor cortices. Proc Natl Acad Sci U S A 111:6816-6821. CrossRef Medline

Chang JY, Janak PH, Woodward DJ (2000) Neuronal and behavioral correlations in the medial prefrontal cortex and nucleus accumbens during cocaine self-administration by rats. Neuroscience 99:433-443. Medline

Chen BT, Yau HJ, Hatch C, Kusumoto-Yoshida I, Cho SL, Hopf FW, Bonci A (2013) Rescuing cocaine-induced prefrontal cortex hypoactivity prevents compulsive cocaine seeking. Nature 496:359362. CrossRef Medline

Childress AR, Mozley PD, McElgin W, Fitzgerald J, Reivich M, O'Brien CP (1999) Limbic activation during cue-induced cocaine craving. Am J Psychiatry 156:11-18. CrossRef Medline

Day JJ, Carelli RM (2007) The nucleus accumbens and Pavlovian reward learning. Neuroscientist 13:148-159. CrossRef

Ehrman RN, Robbins SJ, Childress AR, O'Brien CP (1992) Conditioned responses to cocaine-related stimuli in cocaine abuse patients. Psychopharmacology 107:523-529. Medline

Everitt BJ, Robbins TW (2005) Neural systems of reinforcement for drug addiction: from actions to habits to compulsion. Nat Neurosci 8:1481-1489. CrossRef Medline

Fuster JM (2001) The prefrontal cortex-an update: time is of the essence. Neuron 30:319-333. Medline

Ghitza UE, Fabbricatore AT, Prokopenko V, Pawlak AP, West MO (2003) Persistent cue-evoked activity of accumbens neurons after prolonged abstinence from self-administered cocaine. J Neurosci 23:7239-7245. Medline

Goldstein RZ, Volkow ND (2011) Dysfunction of the prefrontal cortex in addiction: neuroimaging findings and clinical implications. Nat Rev Neurosci 12:652-669. CrossRef Medline

Groman SM, Lee B, Seu E, James AS, Feiler K, Mandelkern MA, London ED, Jentsch JD (2012) Dysregulation of D(2)-mediated dopamine transmission in monkeys after chronic escalating methamphetamine exposure. J Neurosci 32:5843-5852. CrossRef Medline

Hess EH, Polt JM (1960) Pupil size as related to interest value of visual stimuli. Science 132:349-350. Medline

Hollander JA, Carelli RM (2007) Cocaine-associated stimuli increase cocaine seeking and activate accumbens core neurons after abstinence. J Neurosci 27:3535-3539. CrossRef Medline

Hu Y, Salmeron BJ, Gu H, Stein EA, Yang Y (2015) Impaired functional connectivity within and between frontostriatal circuits and its association with compulsive drug use and trait impulsivity in cocaine addiction. JAMA Psychiatry 72:584-592. CrossRef Medline

Ishikawa A, Ambroggi F, Nicola SM, Fields HL (2008) Dorsomedial prefrontal cortex contribution to behavioral and nucleus accumbens neuronal responses to incentive cues. J Neurosci 28:50885098. CrossRef Medline

Jentsch JD, Taylor JR (1999) Impulsivity resulting from frontostriatal dysfunction in drug abuse: implications for the control of behavior by reward-related stimuli. Psychopharmacology 146:373-390. Medline
Jodo E, Chiang C, Aston-Jones G (1998) Potent excitatory influence of prefrontal cortex activity on noradrenergic locus coeruleus neurons. Neuroscience 83:63-79. Medline

Joshi S, Li Y, Kalwani RM, Gold JI (2016) Relationships between pupil diameter and neuronal activity in the locus coeruleus, colliculi, and cingulate cortex. Neuron 89:221-234. CrossRef Medline Kalivas PW, Volkow N, Seamans J (2005) Unmanageable motivation in addiction: a pathology in prefrontal-accumbens glutamate transmission. Neuron 45:647-650. CrossRef Medline

LaLumiere RT, Niehoff KE, Kalivas PW (2010) The infralimbic cortex regulates the consolidation of extinction after cocaine selfadministration. Learn Mem 17:168-175. CrossRef Medline

Lüthi A, Lüscher C (2014) Pathological circuit function underlying addiction and anxiety disorders. Nat Neurosci 17:1635-1643. CrossRef

Maas LC, Lukas SE, Kaufman MJ, Weiss RD, Daniels SL, Rogers VW, Kukes TJ, Renshaw PF (1998) Functional magnetic resonance imaging of human brain activation during cue-induced cocaine craving. Am J Psychiatry 155:124-126. CrossRef Medline

MacAskill AF, Cassel JM, Carter AG (2014) Cocaine exposure reorganizes cell type- and input-specific connectivity in the nucleus accumbens. Nat Neurosci 17:1198-1207. CrossRef Medline

Mahler SV, Aston-Jones GS (2012) Fos activation of selective afferents to ventral tegmental area during cue-induced reinstatement of cocaine seeking in rats. J Neurosci 32:13309-13326. CrossRef Medline

McCracken CB, Grace AA (2013) Persistent cocaine-induced reversal learning deficits are associated with altered limbic corticostriatal local field potential synchronization. J Neurosci 33:1746917482. CrossRef Medline

McGinley MJ, David SV, McCormick DA (2015) Cortical membrane potential signature of optimal states for sensory signal detection. Neuron 87:179-192. CrossRef Medline

Moorman DE, Aston-Jones G (2015) Prefrontal neurons encode context-based response execution and inhibition in reward seeking and extinction. Proc Natl Acad Sci U S A 112:9472-9477. CrossRef Medline

Moorman DE, James MH, McGlinchey EM, Aston-Jones G (2015) Differential roles of medial prefrontal subregions in the regulation of drug seeking. Brain Res 1628:130-146.

Muñoz-Cuevas FJ, Athilingam J, Piscopo D, Wilbrecht L (2013) Cocaine-induced structural plasticity in frontal cortex correlates with conditioned place preference. Nat Neurosci 16:1367-1369. CrossRef Medline

O'Brien CP, Childress AR, Ehrman R, Robbins SJ (1998) Conditioning factors in drug abuse: can they explain compulsion? J Psychopharmacol 12:15-22.

Pascoli V, Terrier J, Espallergues J, Valjent E, O'Connor EC, Lüscher C (2014) Contrasting forms of cocaine-evoked plasticity control components of relapse. Nature 509:459-464. CrossRef Medline

Pessoa $L$ (2008) On the relationship between emotion and cognition. Nat Rev Neurosci 9:148-158. CrossRef Medline

Peters J, LaLumiere RT, Kalivas PW (2008) Infralimbic prefrontal cortex is responsible for inhibiting cocaine seeking in extinguished rats. J Neurosci 28:6046-6053. CrossRef Medline

Pickens CL, Airavaara M, Theberge F, Fanous S, Hope BT, Shaham $Y(2011)$ Neurobiology of the incubation of drug craving. Trends Neurosci 34:411-420. CrossRef Medline

Rebec GV, Sun W (2005) Neuronal substrates of relapse to cocaineseeking behavior: role of prefrontal cortex. J Exp Anal Behav 84:653-666. Medline

Reimer J, Froudarakis E, Cadwell CR, Yatsenko D, Denfield GH, Tolias AS (2014) Pupil fluctuations track fast switching of cortical states during quiet wakefulness. Neuron 84:355-362. CrossRef Medline

Robinson TE, Berridge KC (1993) The neural basis of drug craving: an incentive-sensitization theory of addiction. Brain Res Rev 18: 247-291. Medline 
Robinson TE, Berridge KC (2008) Review. The incentive sensitization theory of addiction: some current issues. Philos Trans R Soc Lond B Biol Sci 363:3137-3146. CrossRef Medline

Robinson TE, Yager LM, Cogan ES, Saunders BT (2014) On the motivational properties of reward cues: individual differences. Neuropharmacology 76:450-459. CrossRef Medline

Rosse RB, Alim TN, Johri SK, Hess AL, Deutsch SI (1995) Anxiety and pupil reactivity in cocaine dependent subjects endorsing cocaineinduced paranoia: preliminary report. Addiction 90:981-984. Medline

Sara SJ, Hervé-Minvielle A (1995) Inhibitory influence of frontal cortex on locus coeruleus neurons. Proc Natl Acad Sci U S A 92: 6032-6036. Medline

Schwarz LA, Miyamichi K, Gao XJ, Beier KT, Weissbourd B, DeLoach KE, Ren J, Ibanes S, Malenka RC, Kremer EJ, Luo L (2015) Viral-genetic tracing of the input-output organization of a central noradrenaline circuit. Nature 524:88-92. CrossRef Medline

Shobe JL, Claar LD, Parhami S, Bakhurin KI, Masmanidis SC (2015) Brain activity mapping at multiple scales with silicon microprobes containing 1,024 electrodes. J Neurophysiol 114:2043-2052. CrossRef Medline

Storey GP, Gonzalez-Fernandez G, Bamford IJ, Hur M, McKinley JW, Heimbigner L, Minasyan A, Walwyn WM, Bamford NS (2016) Nicotine modifies corticostriatal plasticity and amphetamine rewarding behaviors in mice $(1,2,3)$. eNeuro 3 . CrossRef Medline

Sun W, Rebec GV (2006) Repeated cocaine self-administration alters processing of cocaine-related information in rat prefrontal cortex. J Neurosci 26:8004-8008. CrossRef Medline
Trantham H, Szumlinski KK, McFarland K, Kalivas PW, Lavin A (2002) Repeated cocaine administration alters the electrophysiological properties of prefrontal cortical neurons. Neuroscience 113:749753. Medline

Tseng KY, Mallet N, Toreson KL, Le Moine C, Gonon F, O'Donnell P (2006) Excitatory response of prefrontal cortical fast-spiking interneurons to ventral tegmental area stimulation in vivo. Synapse 59:412-417. CrossRef Medline

Vinck M, Batista-Brito R, Knoblich U, Cardin JA (2015) Arousal and locomotion make distinct contributions to cortical activity patterns and visual encoding. Neuron 86:740-754. CrossRef Medline

Voorn P, Vanderschuren LJ, Groenewegen HJ, Robbins TW, Pennartz CM (2004) Putting a spin on the dorsal-ventral divide of the striatum. Trends Neurosci 27:468-474. CrossRef Medline

West EA, Saddoris MP, Kerfoot EC, Carelli RM (2014) Prelimbic and infralimbic cortical regions differentially encode cocaineassociated stimuli and cocaine-seeking before and following abstinence. Eur J Neurosci 39:1891-1902. CrossRef Medline

Wexler BE, Gottschalk CH, Fulbright RK, Prohovnik I, Lacadie CM, Rounsaville BJ, Gore JC (2001) Functional magnetic resonance imaging of cocaine craving. Am J Psychiatry 158:86-95. CrossRef Medline

Wilcox CE, Teshiba TM, Merideth F, Ling J, Mayer AR (2011) Enhanced cue reactivity and fronto-striatal functional connectivity in cocaine use disorders. Drug Alcohol Depend 115:137-144. CrossRef Medline 